\title{
Design, fabrication, and high-gradient testing of $X$-band choke-mode damped structures
}

\author{
Xiaowei Wu, Hao Zha, Jiaru Shi, ${ }^{*}$ and Huaibi Chen \\ Department of Engineering Physics, Tsinghua University, Beijing, CN-100086, China \\ and Key Laboratory of Particle Radiation Imaging, Tsinghua University, \\ Ministry of Education, Beijing, CN-100086, China \\ Tetsuo Abe, Toshiyasu Higo, and Shuji Matsumoto \\ KEK, High Energy Accelerator Research Organization, Tsukuba, 305-0801, Japan
}

(Received 23 December 2018; published 7 March 2019)

\begin{abstract}
Choke-mode accelerating structures are higher-order-mode (HOM) damped structures that are relatively simple to fabricate and have low surface magnetic fields. $C$-band choke-mode accelerating structures have been successfully applied in free electron lasers. However, studies on $X$-band choke-mode structures for the main linac of the Compact Linear Collider (CLIC) currently remain at the theoretical design stage, and the high-gradient performance of a choke remains unknown. In this study, we designed and fabricated five different single-cell choke-mode accelerating structures and subjected them to high-gradient tests to study related radio frequency (rf) breakdown characteristics. High electrical field and small choke gap caused serious breakdowns in the choke, which mainly limited high-gradient performance. The choke-mode accelerating structure reached $121 \mathrm{MV} / \mathrm{m}$ at a breakdown rate of $8.30 \times 10^{-4}$ per pulse per meter and a flat top pulse width of $250 \mathrm{~ns}$. A new quantity proposed to give the high-gradient performance limitation of choke-mode accelerating structures due to rf breakdown. The new quantity was obtained from the summary of the high-gradient experiments and can be used as reference for high-gradient choke-mode accelerating structure design.
\end{abstract}

DOI: 10.1103/PhysRevAccelBeams.22.031001

\section{INTRODUCTION}

The choke-mode accelerating structure was first proposed by Tsumoru Shintake [1]. It was designed to use choke to contain the fundamental accelerating mode inside the cavity while allowing for parasitic higher-order-modes (HOMs) to be propagated to rf loads where their energy is absorbed. As HOM damping structures, choke-mode accelerating structures have a simple fabrication process and low surface magnetic fields [1,2]. Thus, the structures have been studied for two decades and was successfully applied in the linear accelerator of Spring-8 [3-7]. The $X$-band choke-mode accelerating structure is currently being studied as an alternative design for the accelerating structure of the compact linear collider (CLIC) main linac in collaboration between CERN and Tsinghua University [2,8-27]. The choke-mode design has several potential advantages to other types of heavy damped structures [2,28-31]: (i) it has lower

\footnotetext{
*shij@tsinghua.edu.cn
}

Published by the American Physical Society under the terms of the Creative Commons Attribution 4.0 International license. Further distribution of this work must maintain attribution to the author(s) and the published article's title, journal citation, and DOI. surface magnetic field compared to waveguide damped structures, which results in lower pulsed temperature rise; (ii) there are no bonding joints of the disks in high magnetic field; (iii) the choke structure is axially symmetric so can be manufactured by turning, which potentially greatly reduces the total manufacturing cost. The choke design does however have certain disadvantages [1,2]: choke reduces shunt impedance and $\mathrm{R} / \mathrm{Q}$, the larger volume and surface area make the choke-mode cell a lower rf-beam efficiency.

Vacuum arcing in the structures, also referred to as breakdown, will lower beam quality and damage the structure surface [32-36]. Hence, the tendency of normal conducting rf structures to experience breakdown at high fields poses the main limitation on practically usable accelerating gradient [37-46]. However, the high-gradient performance of the $X$-band choke is currently unknown.

Single-cell experimental study is an important way to study the performance of accelerating structures. It was first conducted by V.A. Dolgashev from SLAC National Accelerator Laboratory (SLAC) and Y. Higashi from KEK [47-52]. Given that single-cell accelerating structures are easy to fabricate and have short high-gradient test time, experimental studies are suitable for comparing the high-gradient performance of different accelerating structures [53,54]. 
Five different choke-mode single-cell accelerating structures and one reference structure were designed, fabricated, assembled, and tuned in Tsinghua University [55]. We performed high-gradients test to examine the breakdown and high-gradient properties of $X$-band choke-mode structures. The tests were conducted in New $X$-band Test Facility (Nextef) at KEK [56]. We compared the highgradient performance of different chokes to determine how choke dimension affects breakdown in the structures. A new quantity was proposed to give the high-gradient performance limitation of choke-mode accelerating structures due to rf breakdown.

\section{DESIGN OF CHOKE-MODE ACCELERATING STRUCTURES}

A single-cell structure consists of an input coupler cell, high-gradient middle cell(s), and end cell [51]. Five chokemode single-cell structures and one reference cylinder structure were designed, fabricated, assembled, and tuned at Tsinghua University. One of the choke-mode structure was based on the current prototype choke-mode accelerating structure design for CLIC [2,13,31], whereas the reference structure was based on the single-cell structure with the iris aperture of $3.75 \mathrm{~mm}$ and the iris thickness of $2.6 \mathrm{~mm}$ from SLAC [50,51]. The other choke-mode accelerating structures were designed to compare the effects of choke dimension on high-gradient performance [57]. The HFSS model of choke-mode accelerating structure is shown in Fig. 1. The middle cell with the choke is the testing cell.

In the SLAC experiments two types of chokes were tested. The first one had choke gap of $1 \mathrm{~mm}$. The high-gradient test has shown that the majority of breakdowns were in the choke and the established gradient was below $80 \mathrm{MV} / \mathrm{m}$ [50]. As a consequence of these results, the choke gap was increased to largest practical of $4 \mathrm{~mm}$. Performance of the structure with $4 \mathrm{~mm}$ choke was the same as a structure without the choke. The geometry of $4 \mathrm{~mm}$ choke as well as full-cell choke could be found in Ref. [58]. Transient regime, where the rf breakdowns were partially in the choke and partially in the cavity (with choke gap between $1 \mathrm{~mm}$ and $4 \mathrm{~mm}$ ) were not studied in these experiments.

The maximum electrical field at the choke is related to the choke dimension according to the basic principles of choke-mode accelerating structures [1,2,31]. Five chokemode accelerating structures with different maximum choke surface electrical field and choke gap dimensions

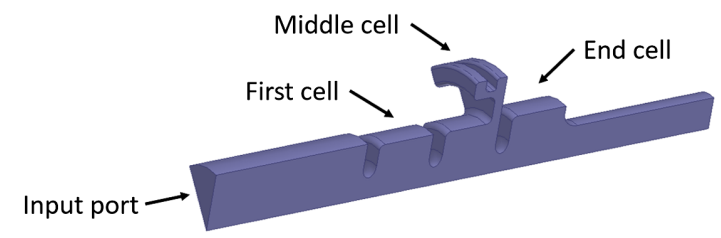

FIG. 1. HFSS model of choke-mode accelerating structure.

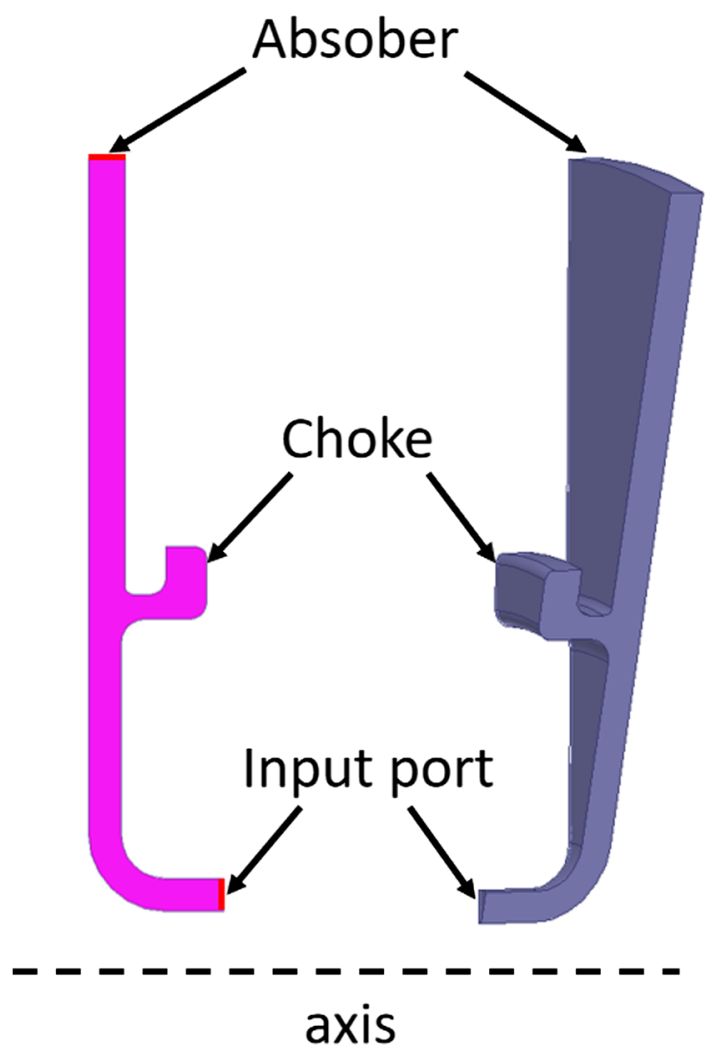

FIG. 2. Structures to test the reflection at choke.

were designed. The width of the choke gap was maintained at $2.5 \mathrm{~mm}$ for a stable mechanical design.

\section{A. Middle cell design}

The middle cell was designed first. The choke reflects the accelerating mode, but unwanted HOMs can pass the choke to be absorbed in the load. The external quality factor of the testing cell, $Q_{\text {ext }}$, was defined as follows:

$$
Q_{\mathrm{ext}}=\frac{\omega U}{P_{\mathrm{r}}},
$$

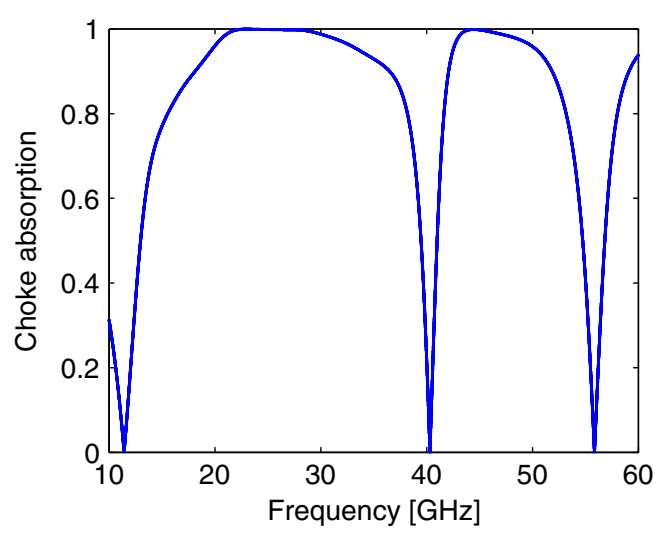

FIG. 3. Absorbing curve of THU-CHK-\#1. Choke absorption is $\sqrt{1-S_{11}^{2}}$. 

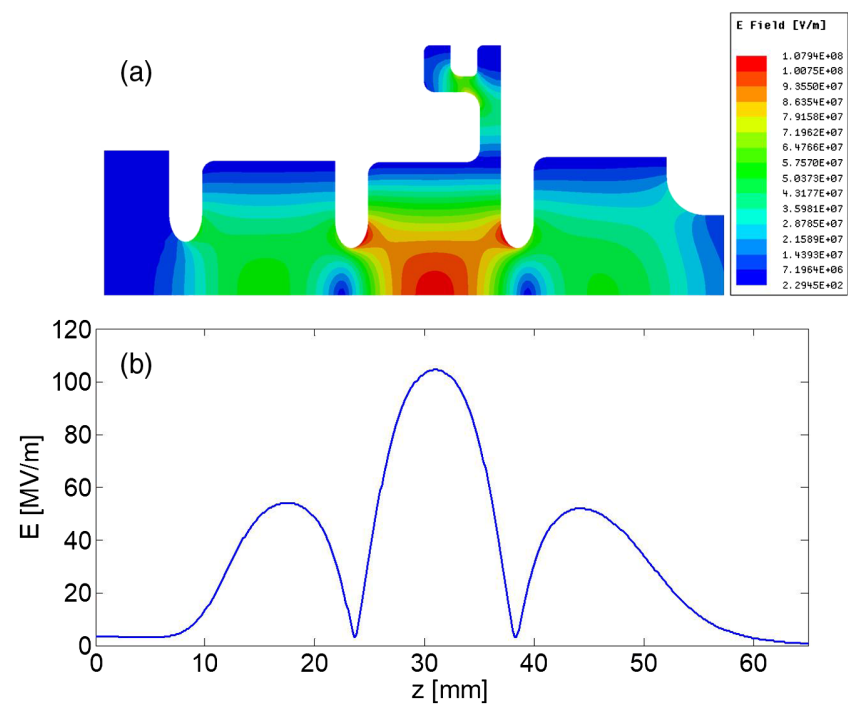

FIG. 4. Electrical field distribution of THU-CHK-\#1 at input power of $1 \mathrm{MW}$. (a) Electrical field on the cross section. (b) Electrical field along the z-axis.

where $\omega$ is angular frequency, $U$ is the storage energy, $P_{\mathrm{r}}$ is the power absorbed by the radial line. A new quantity for choke optimization, $R_{\text {leak }}$, was defined as follows:

$$
R_{\text {leak }}=10 \log \left(\frac{P_{\mathrm{r}}}{P_{\text {loss }}}\right)=10 \log \left(\frac{Q_{0}}{Q_{\text {ext }}}\right),
$$

where $P_{\text {loss }}$ is the cavity surface loss, and $Q_{0}$ is the intrinsic quality factor. $R_{\text {leak }}$ should be reduced for the suppression of the leakage of the accelerating mode to the radial line. $R_{\text {leak }}$ was kept below $-30 \mathrm{~dB}$ in the design by taking the limits of the power absorption of the actual load into account [20].

The HFSS model shown in Fig. 2 was used to determine the absorption of HOMs by the choke. The radial line with a choke is connected to a coaxial line, which can be defined as a waveguide port in the simulation. The outer layer of the radial line was filled with absorber [2,31].

The results of HFSS simulation is shown in Fig. 3. The zero absorption points in the curve indicate that modes at these frequencies are fully reflected by the choke, which are so called parasitic modes. Some dipole modes have high kick factor between $15 \mathrm{GHz}$ and $40 \mathrm{GHz}$ from the wakefield impedance spectrum of choke-mode accelerating structure [2]. The parasitic modes reflected by the choke would make a large contribution to the total transverse wakefield potential if they are within this range. The fully reflected frequencies were kept out of this region in the designs.

\section{B. Design of the full structure}

The single-cell structure was tuned to work at $11.424 \mathrm{GHz}$ and critical coupled by optimizing the dimensions of the first and end cells shown in Fig. 1. The electrical field distribution is shown in Fig. 4. The field in the middle cell is approximately twice of that in the first and end cells.

The electrical and magnetic fields of the middle cell of each structure are shown in Fig. 5.
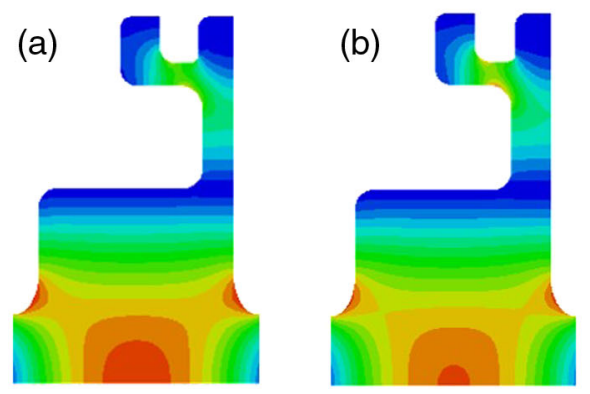

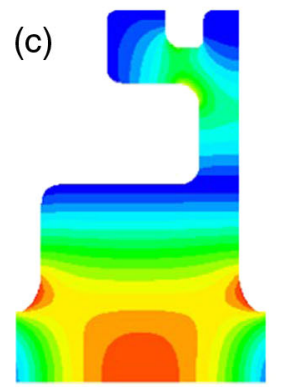

(d)
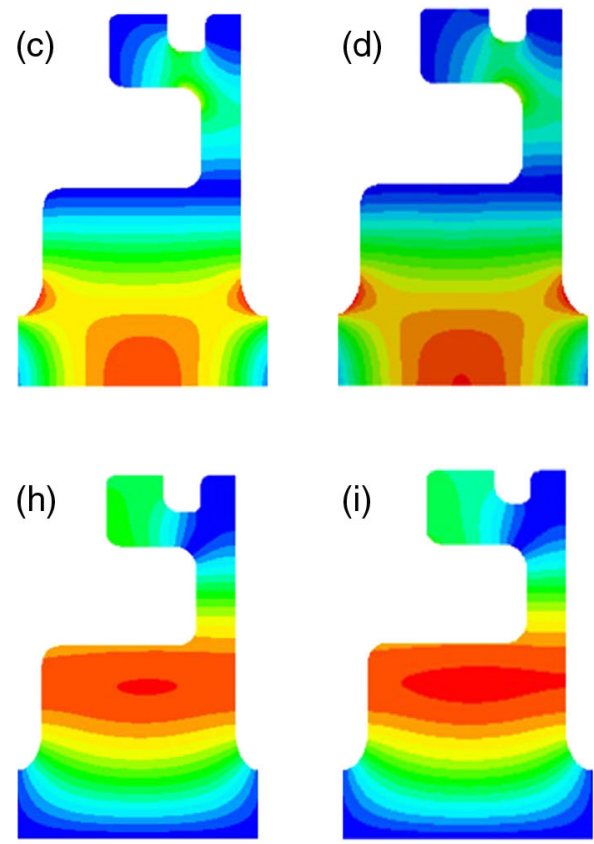

(i)

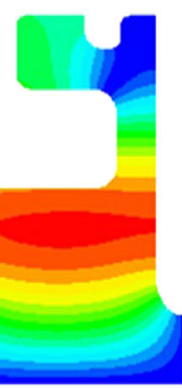

(e)
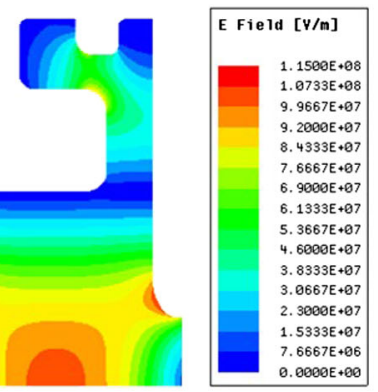

(j)

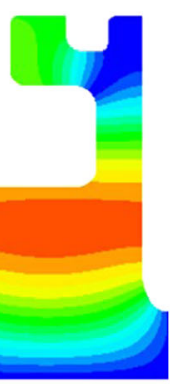

FIG. 5. Electrical and magnetic fields of the middle cells of choke-mode accelerating structures. The loss power of the whole structure is normalized to $1 \mathrm{MW}$. (a)-(e) are the electrical fields of THU-CHK-\#1 to THU-CHK-\#5. (f)-(j) are the magnetic fields of THU-CHK\#1 to THU-CHK-\#5. 
TABLE I. Information of the choke-mode structures.

\begin{tabular}{lccccccccc}
\hline \hline THU- & $D[\mathrm{~mm}]$ & $R_{\mathrm{E}}$ & $R_{\mathrm{c}}$ & $E_{\text {peak }}[\mathrm{MV} / \mathrm{m}]$ & $H_{\max }[\mathrm{MA} / \mathrm{m}]$ & $S_{c}{ }^{\mathrm{a}}\left[\mathrm{MW} / \mathrm{mm}^{2}\right]$ & Stored energy $[\mathrm{J}]$ & $Q_{0}$ & Shunt impedance $[\mathrm{M} \Omega / \mathrm{m}]^{\mathrm{b}}$ \\
\hline REF & $\ldots$ & 2.05 & $\ldots$ & 129.9 & 0.212 & 1.511 & 0.125 & 9010 & 143.0 \\
CHK-\#1 & 1.26 & 2.10 & 0.759 & 108.6 & 0.182 & 1.115 & 0.104 & 7519 & 92.29 \\
CHK-\#2 & 1.26 & 2.05 & 0.923 & 104.3 & 0.172 & 1.037 & 0.100 & 7247 & 82.84 \\
CHK-\#3 & 1.89 & 2.04 & 0.727 & 110.4 & 0.185 & 1.151 & 0.111 & 8006 & 98.38 \\
CHK-\#4 & 2.21 & 2.06 & 0.687 & 112.1 & 0.187 & 1.186 & 0.114 & 8210 & 102.8 \\
CHK-\#5 & 1.88 & 2.05 & 0.836 & 103.0 & 0.180 & 1.093 & 0.109 & 7864 & 91.11 \\
\hline \hline
\end{tabular}

${ }^{\mathrm{a}} S_{\mathrm{c}}$ is the maximum modified Poynting vector [59].

${ }^{\mathrm{b}}$ Shunt impedance of the middle cell.

The choke field ratio $R_{\mathrm{c}}$ is the maximum electrical field in the choke and is divided by the maximum surface electrical field of the structure. Define $R_{\mathrm{E}}$ as the ratio of the maximum surface electrical field to the accelerating field $\left(E_{\text {acc }}\right)$ in the middle cell simulation. Meanwhile, $R_{\mathrm{p}}$ is the ratio between the maximum surface electrical field $\left(E_{\text {peak }}\right)$ and the square root of the surface power loss in the full structure.

$$
R_{\mathrm{p}}=\frac{E_{\text {peak }}[\mathrm{MV} / \mathrm{m}]}{\sqrt{P_{\text {loss }}[\mathrm{MW}]}},
$$

where $P_{\text {loss }}$ is the surface power loss. $R_{\mathrm{p}}$ equals as $E_{\text {peak }}$ when the power loss is $1 \mathrm{MW}$. Then $E_{\text {acc }}$ of the choke-mode accelerating structure can be calculated by:

$$
E_{\text {acc }}=\frac{R_{\mathrm{p}}}{R_{\mathrm{E}}} \times \sqrt{P_{\text {loss }}}=\frac{R_{\mathrm{p}}}{R_{\mathrm{E}}} \times \sqrt{P_{\text {in }}-P_{\text {ref }}},
$$

where $P_{\text {in }}$ and $P_{\text {ref }}$ are the input and reflected power in the high-gradient test, respectively. The rf parameters of the single-cell structures are shown in Table I. The values shown in Table I are normalized to $1 \mathrm{MW}$ of lost power. D is the choke gap size in $\mathrm{mm}$.

\section{FABRICATION, LOW-POWER RF TESTS, AND PREPARATION}

Each choke-mode accelerating structure consisted of six disks, as shown in Fig. 6. All the disks were manufactured by turning because of their symmetric designs. The disks and the coupler parts of the choke-mode accelerating structures were machined by Tsinghua University, as shown in Fig. 7. The testing cell consisted of two disks. The parts were cleaned, etched, and bonded following the procedures based on global linear collider (GLC) fabricating technology $[60,61]$. The procedures were the same as that of T24_THU_\#1 [62].

In the preparation of the assembly of the choke-mode accelerating structure, the Tsinghua equipment and fabrication procedures were validated by high temperature diffusion bonding and mechanically measuring a test assembly. The quality of the bonding was verified by cutting the test structure after bonding and confirming that the inner dimension change owing to the bonds below $10 \mu \mathrm{m}$. After the successful completion of the bonding tests, the individual parts of the choke-mode accelerating structures were diffusion bonded in a hydrogen furnace at Tsinghua University [62]. The coupler parts and flanges were gold brazed to the main cell stack. Then, tuning was performed in nitrogen flow at $25^{\circ} \mathrm{C}$. The structure was

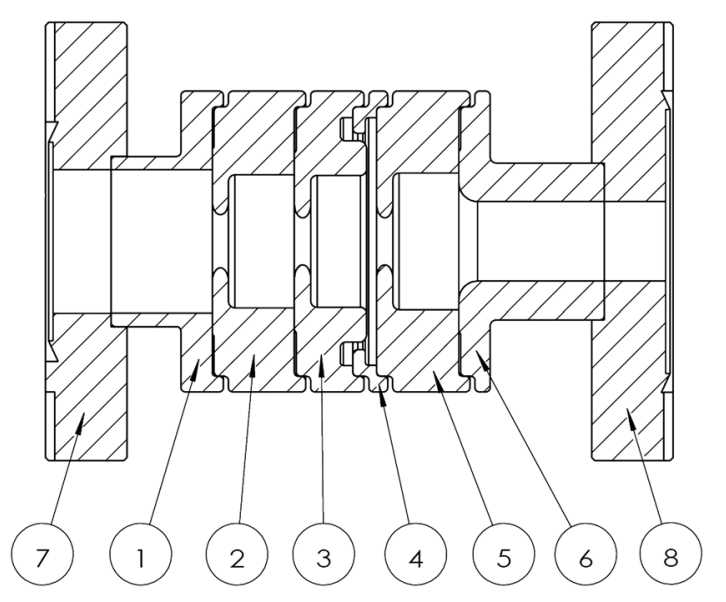

FIG. 6. Mechanical design of THU-CHK-\#1. No. 1 to 6 are the disks of main cavity. No. 7 and No. 8 are Pearson flange [63] and ICF70 flange.

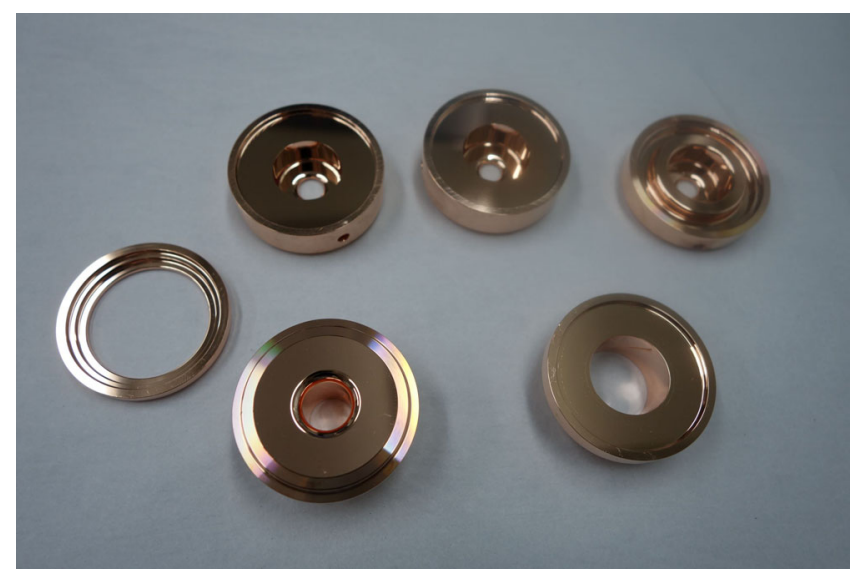

FIG. 7. Disks of choke-mode accelerating structure. 


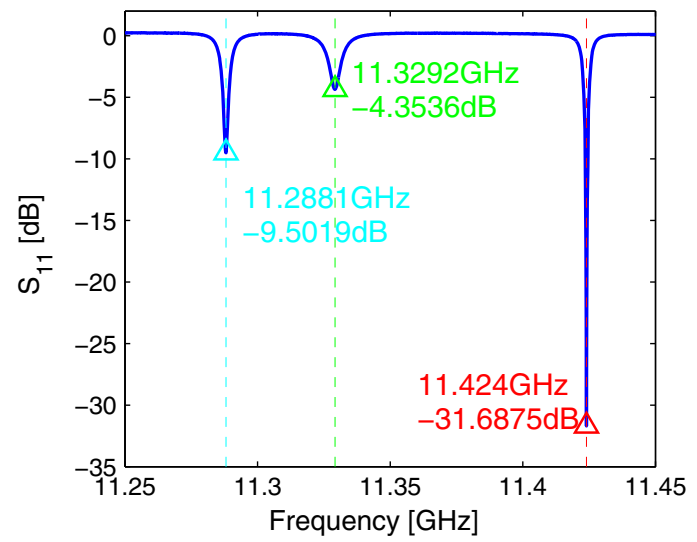

FIG. 8. Lower-power rf measurement result of THU-CHK-\#3 after tuning.

tuned to $11.424 \mathrm{GHz}$ at the working temperature of $30^{\circ} \mathrm{C}$, which is the standard cooling water temperature at Nextef. The tuning results are shown in Fig. 8. Vacuum baking was performed in Tsinghua University. This step differed from the CLIC baseline procedure because of the temperature limitation in the vacuum furnace at Tsinghua University. Vacuum baking was performed at $500{ }^{\circ} \mathrm{C}$ [62]. The structures were sealed by blind flanges with metallic gaskets, and the vacuum was pumped independently from the furnace during baking. The structures were kept under vacuum after baking by sealing with a valve and were shipped to KEK under vacuum.

\section{HIGH-GRADIENT TEST}

A high-gradient test was conducted after the structure was installed in Shield-B $[55,64]$ of Nextef at KEK. Shield-B is driven by an $X$-band klystron working at $11.424 \mathrm{GHz}$ with the repetition rate of $50 \mathrm{~Hz}$ and peak power of $50 \mathrm{MW}$. Shield-B is aiming at basic high-gradient study by testing single-cell structures $[53,54]$.

The setup of Shield-B is shown in Fig. 9. Two Faraday cups were placed at the power feed end and power cut end to collect the field emission current. The incident wave and reflected wave were monitored by the directional couplers shown in Fig. 9. These signals were monitored pulse for breakdown detection [38,56,65-69].

The filling time of the single-cell structures is around $100 \mathrm{~ns}$. Therefore, $E_{\text {acc }}$ excited in the structure is not flat when the pulse width of the rectangular input is several hundreds of nanoseconds, as shown in Fig. 10.

Step-pulse input was used in the high-gradient test to obtain stable $E_{\text {acc }}$ in the structure. Flat top of electrical field can be achieved in the second step by adjusting the amplitude of the two steps, as shown in Fig. 11. The pulse width of the first step was set to $100 \mathrm{~ns}$. The total pulse width was increased by expanding the second step. The flat top pulse width in this paper is the width of the second step, unless explicitly stated otherwise.

Conditioning is the process of gradually improving the structure surface and gradient holding capability through the application of $\mathrm{rf}$ [32]. The conditioning strategy of the single-cell structure is similar to that of T24_THU_\#1 $[62,70]$. Conditioning operation was started with the rf power of the order of hundreds of kilowatts and $100 \mathrm{~ns}$ rectangular pulse, which were progressively increased to the nominal peak power and pulse width. The pulse width was kept constant for extended periods, and the power was ramped by a step, which ranged from 0.02 to $0.05 \mathrm{MW}$, until it exceeded the nominal maximum unloaded accelerating gradient of $100 \mathrm{MV} / \mathrm{m}$. The pulse width of the second step was lengthened after 50 ns or 100 ns steps. Then, input rf power was ramped from a few hundred kilowatts again for the new pulse width.

The interlock system inhibited the subsequent pulse when any jump in the reflected rf signal or field emission current signal was detected. Then, the system was stopped for 30 seconds before the subsequent rf pulse, which is sufficiently long to allow for both the reduction of gas pressure and archiving the waveforms. These interlock events might indicate a breakdown event and were checked during offline data analysis [64]. The system reduced the rf power by approximately $5 \%$ after breakdown detection and

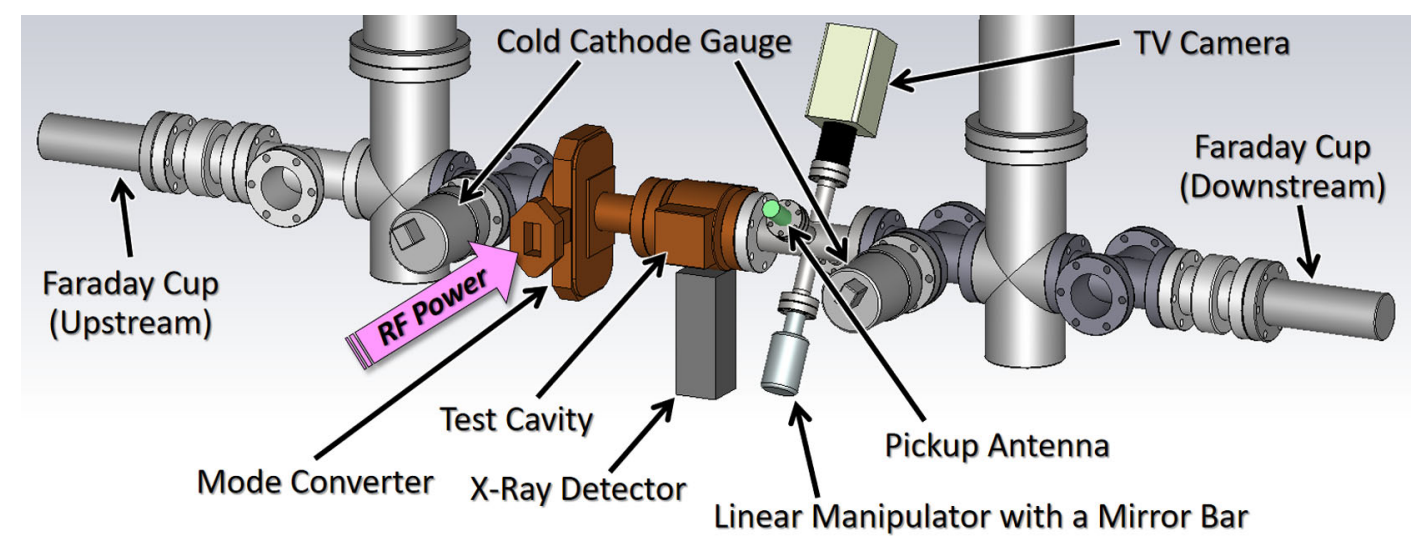

FIG. 9. Shield-B experimental setup. 


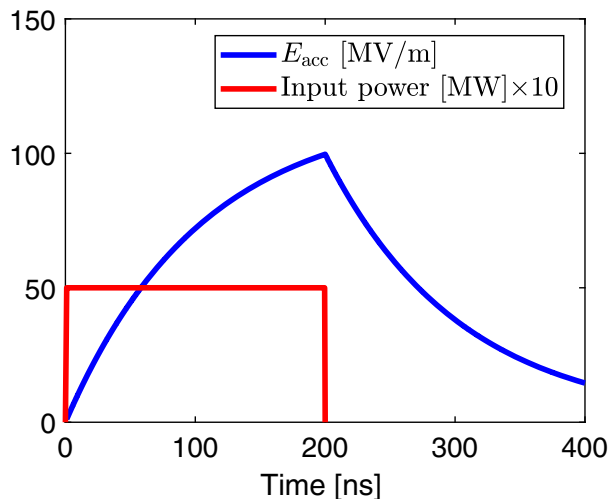

FIG. 10. $200 \mathrm{~ns}$ rectangular input pulse and the $E_{\text {acc }}$ excited in the structure (THU-CHK-\#1).

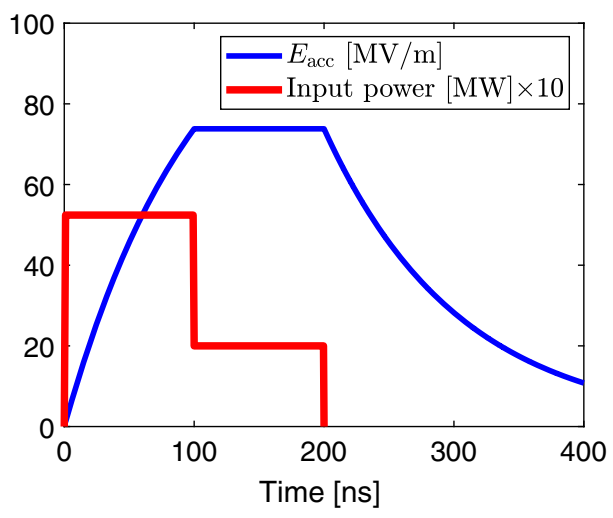

FIG. 11. 200 ns step-pulse input pulse and the $E_{\text {acc }}$ excited in the structure (THU-CHK-\#1).

ramped the power up again by increasing $0.02 \mathrm{MW}$ over a period of $10 \mathrm{~s}$. The breakdown rate (BDR) was kept around or below $2 \times 10^{-5}$ per pulse during the conditioning.

\section{BREAKDOWN PHENOMENON STUDY}

Normal rf pulse signal and typical breakdown signal are shown in Fig. 12 and Fig. 13. An increasing of reflected signal and current flash were observed in the typical breakdown events.

1267 rf breakdown events were collected in the highgradient test of THU-REF. Approximately $98.6 \%$ of the events were accompanied with current flash in the Faraday cup signals. It indicated that the Faraday cups in Shield-B have a good capture of the field emission current. The events without current flash might be occurred in the waveguide or in the mode launcher.

Breakdown events without current flash were observed in the experiment of choke-mode accelerating structures, as shown in Fig. 14, along with the signals shown in Fig. 12 and Fig. 13. The electrons emitted from choke were difficult to be collected by the Faraday cups, which were located at the power feed end and power cut end. The choke

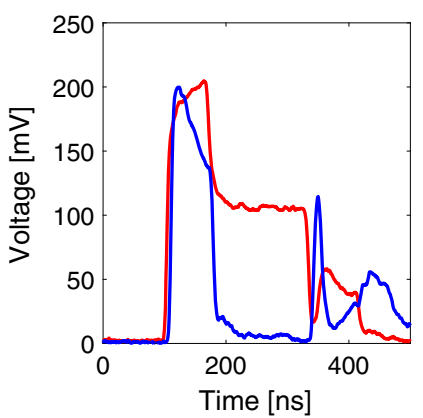

(a)

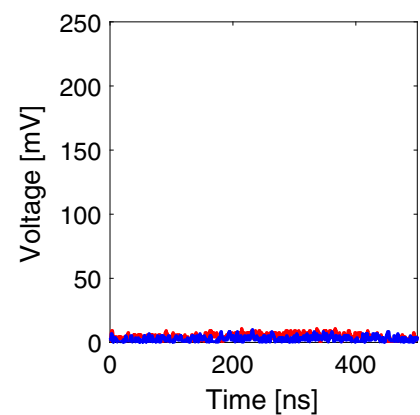

(b)
FIG. 12. Pulse waveform of normal event at flat top pulse width of 250 ns. (a) Directional coupler signals. Red curve is the incident microwave signal and blue curve is the reflected microwave signal. (b) Faraday cup signals. The red curve is the signal of the power feed end and the blue curve is the signal of the power cut end.

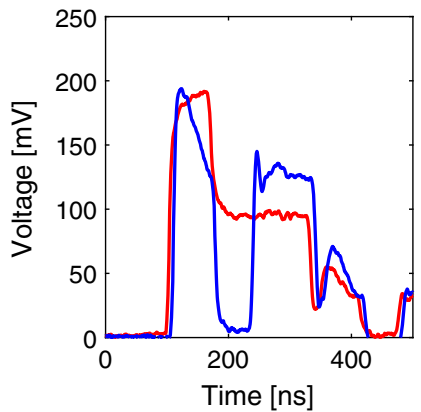

(a)

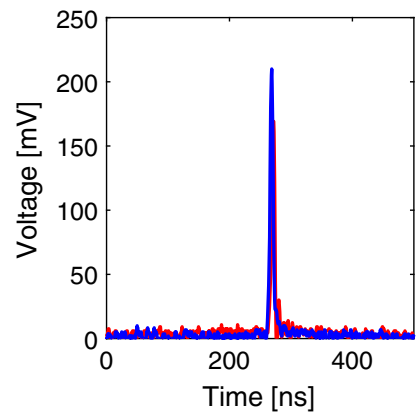

(b)
FIG. 13. Pulse waveform of typical breakdown event with current flash at flat top pulse width of 250 ns. (a) Directional coupler signals. The red curve is the incident microwave signal and the blue curve is the reflected microwave signal. (b) Faraday cup signals. The red curve is the signal of the power feed end and blue curve is the signal of the power cut end.

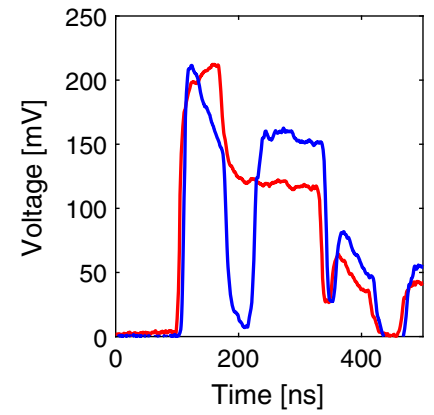

(a)

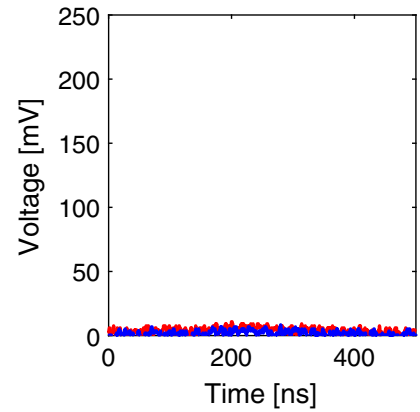

(b)
FIG. 14. Pulse waveform of breakdown event without current flash at flat top pulse width of 250 ns. (a) Directional coupler signals. The red curve is the incident microwave signal and the blue curve is the reflected microwave signal. (b) Faraday cup signals. The red curve is the signal of the power feed end and the blue curve is the signal of the power cut end. 


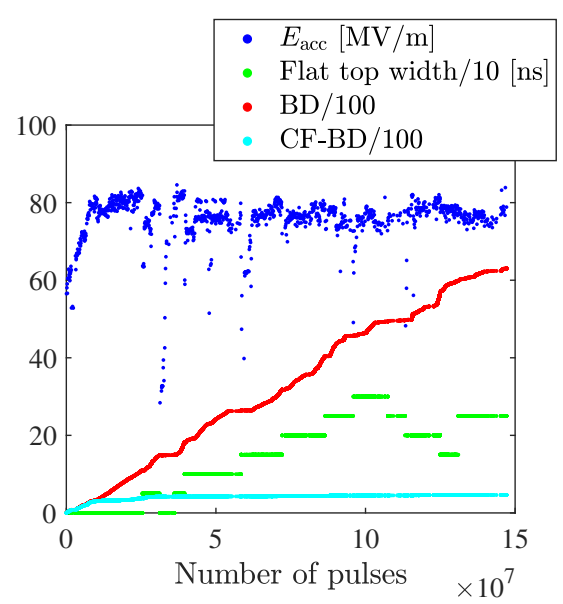

(a)

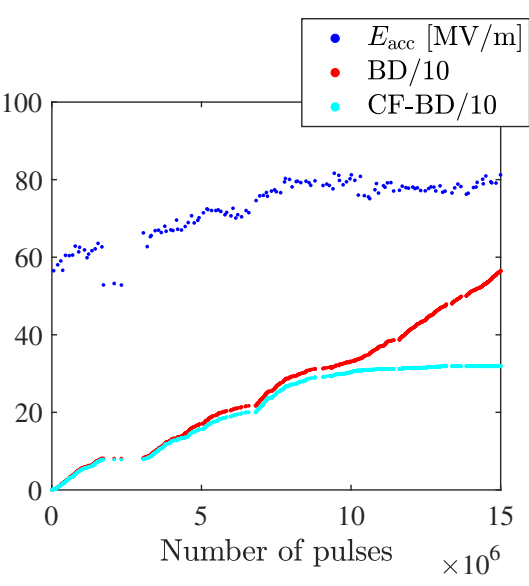

(b)

FIG. 15. Summary of the conditioning history of THU-CHK-\#1. (a) Full history. The blue dots denote $E_{\mathrm{acc}}[\mathrm{MV} / \mathrm{m}]$, the green dots denote flat top pulse width [ns] divided by 10 , the red dots denote total breakdown number divided by 100 , and the cyan dots denote number of CF-BDs divided by 100 . (b) History of the first $1.5 \times 10^{7}$ pulses. The blue dots denote $E_{\text {acc }}[\mathrm{MV} / \mathrm{m}]$, the red dots denote total breakdown number divided by 10, and the cyan dots denote number of CF-BDs divided by 10.

was far from the axis. The breakdown events with current flash (CF-BD) shown in Fig. 13 were speculated to be located in the cylinder cavity or the iris area.

\section{A. High-gradient test history of THU-CHK-\#1}

The summary of the conditioning history of THU-CHK$\# 1$ is shown in Fig. 15. The blue, red, and cyan points represent $E_{\text {acc }}$, the accumulated number of total breakdowns, and the accumulated number of CF-BDs, respectively, as a function of the number of pulses. The accelerating gradient reached $83.9 \mathrm{MV} / \mathrm{m}$ at a flat top pulse width of $250 \mathrm{~ns}$ and a breakdown rate of $1.80 \times 10^{-4}$ per pulse per meter during the conditioning. Current flash signals were only seen in the breakdown events at the early stage of high-gradient tests. Most of the breakdown events were not accompanied with current flash after $1.0 \times 10^{7}$ pulses. $E_{\text {acc }}$ didn't increase efficiently when the breakdowns without current flash dominated the conditioning, as shown in Fig. 15(b). The severe breakdowns in the choke were speculated to limit the accelerating gradient of the structure.

\section{B. High-gradient test history of THU-CHK-\#2}

A large number of breakdown events without current flash were also observed in the experiment of THU-CHK\#2, as shown in Fig. 16. Current flash signals were not seen

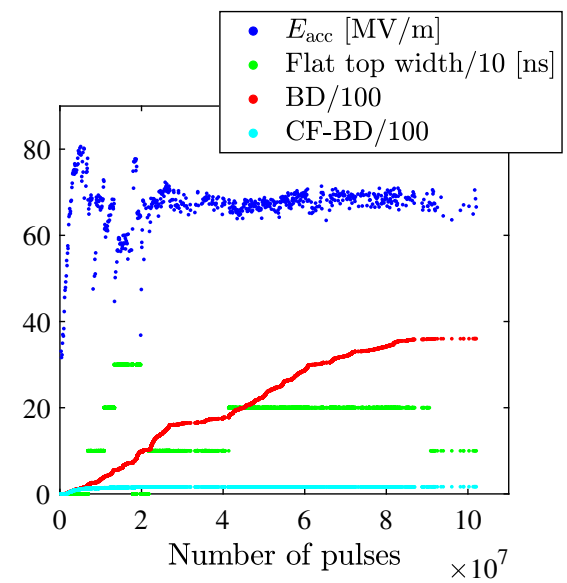

(a)

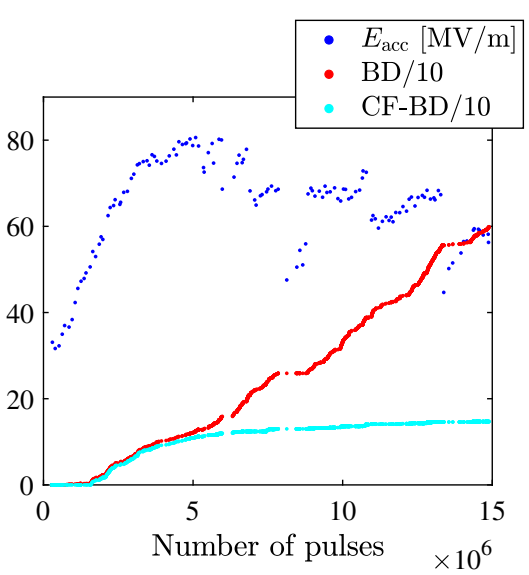

(b)

FIG. 16. Summary of the conditioning history of THU-CHK-\#2. (a) Full history. The blue dots denote $E_{\text {acc }}[\mathrm{MV} / \mathrm{m}]$, the green dots denote flat top pulse width [ns] divided by 10 , the red dots denote total breakdown number divided by 100 , and the cyan dots denote number of CF-BDs divided by 100 . (b) History of the first $1.5 \times 10^{7}$ pulses. The blue dots denote $E_{\text {acc }}[\mathrm{MV} / \mathrm{m}]$, the red dots denote total breakdown number divided by 10, and the cyan dots denote number of CF-BDs divided by 10. 


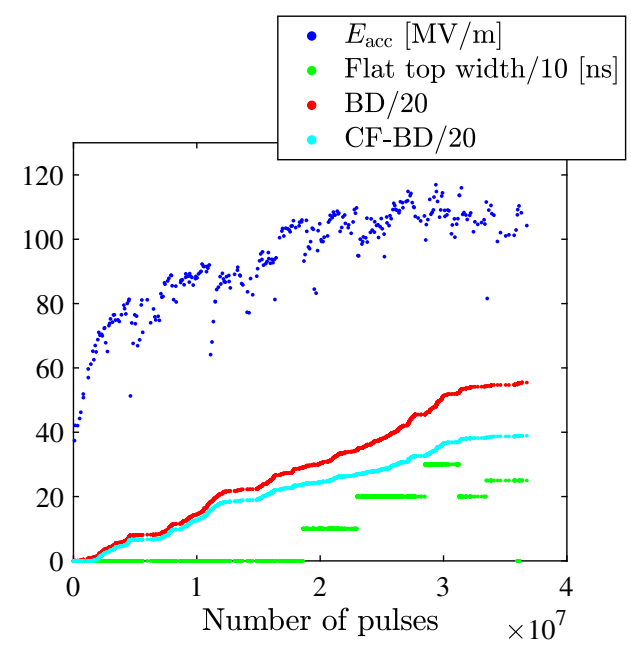

FIG. 17. Summary of the conditioning history of THU-CHK\#3. The blue dots denote $E_{\text {acc }}[\mathrm{MV} / \mathrm{m}]$, the green dots denote flat top pulse width [ns] divided by 10 , the red dots denote total breakdown number divided by 20 , and the cyan dots denote number of CF-BDs divided by 20 .

in most of the rf breakdown events after $0.6 \times 10^{7}$ pulses. The maximum accelerating gradient was $70.2 \mathrm{MV} / \mathrm{m}$ at a flat top pulse width of $200 \mathrm{~ns}$ and a breakdown rate of $4.85 \times 10^{-4}$ per pulse per meter during the conditioning.

\section{High-gradient test history of THU-CHK-\#3}

Breakdown events without current flash were also observed in THU-CHK-\#3, THU-CHK-\#4, and THUCHK-\#5. The summary of the conditioning history of THU-CHK-\#3 is shown in Fig. 17. The accelerating gradient reached $109 \mathrm{MV} / \mathrm{m}$ at a flat top pulse width of

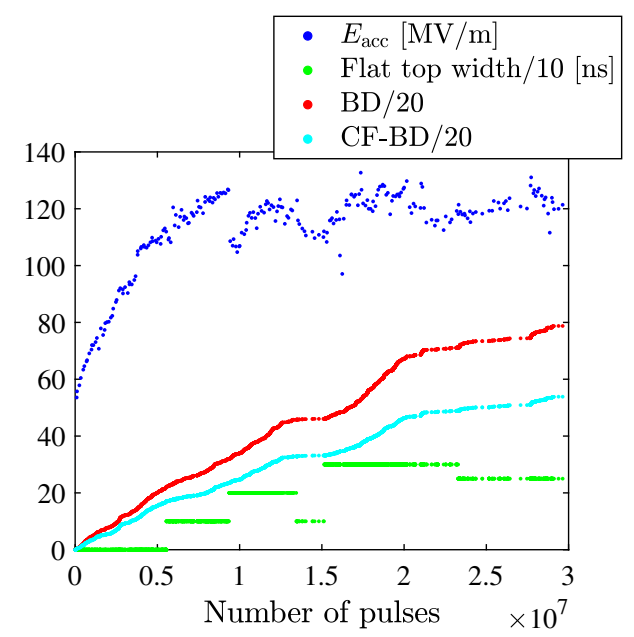

FIG. 18. Summary of the conditioning history of THU-CHK\#4. The blue dots denote $E_{\text {acc }}[\mathrm{MV} / \mathrm{m}]$, the green dots denote flat top pulse width [ns] divided by 10 , the red dots denote total breakdown number divided by 20 , and the cyan dots denote number of CF-BDs divided by 20 .
$250 \mathrm{~ns}$ and a breakdown rate of $4.70 \times 10^{-4}$ per pulse per meter during the conditioning. However, CF-BDs were observed throughout the high-gradient test. This result was different from the results of the first two chokes. Both of the two types of breakdowns occurred in the late stage of the experiment when the $E_{\text {acc }}$ got saturated. It indicated that choke breakdown was not the only factor that limited the structure to achieve a higher $E_{\text {acc }}$. Breakdown in the cylindrical cavity and iris area also limited the improvement of the high-gradient performance.

\section{High-gradient test history of THU-CHK-\#4}

The summary of the conditioning history of THU-CHK\#4 is shown in Fig. 18. The accelerating gradient reached $123 \mathrm{MV} / \mathrm{m}$ at a flat top pulse width of $100 \mathrm{~ns}$ and a breakdown rate of $5.25 \times 10^{-4}$ per pulse per meter during the conditioning.

\section{E. High-gradient test history of THU-CHK-\#5}

The summary of the conditioning history of THU-CHK\#5 is shown in Fig. 19. The accelerating gradient reached $104 \mathrm{MV} / \mathrm{m}$ at a flat top pulse width of $200 \mathrm{~ns}$ and a breakdown rate of $6.79 \times 10^{-4}$ per pulse per meter during the conditioning.

\section{F. High-gradient test history of THU-REF}

The summary of the conditioning history of THU-REF is shown in Fig. 20. The accelerating gradient reached $145 \mathrm{MV} / \mathrm{m}$ at a flat top pulse width of $200 \mathrm{~ns}$ and a breakdown rate of $2.60 \times 10^{-4}$ per pulse per meter. Current flash signals were observed in the entire conditioning of the structure.

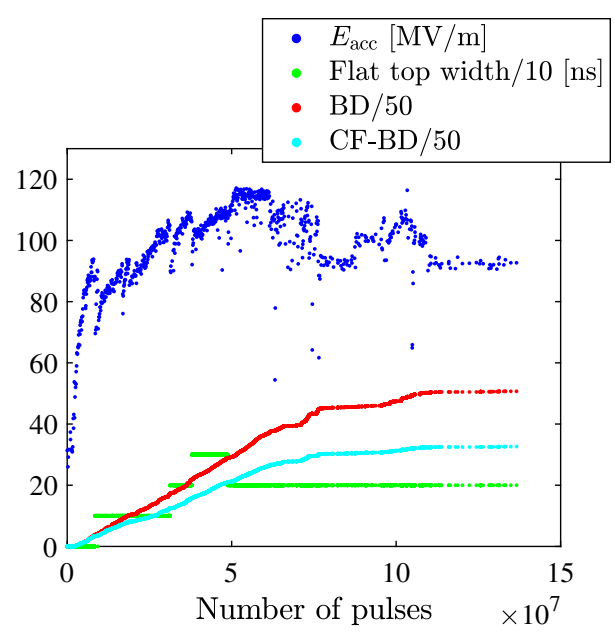

FIG. 19. Summary of the conditioning history of THU-CHK\#5. The blue dots denote $E_{\text {acc }}[\mathrm{MV} / \mathrm{m}]$, the green dots denote flat top pulse width [ns] divided by 10 , the red dots denote total breakdown number divided by 50 , and the cyan dots denote number of CF-BDs divided by 50 . 


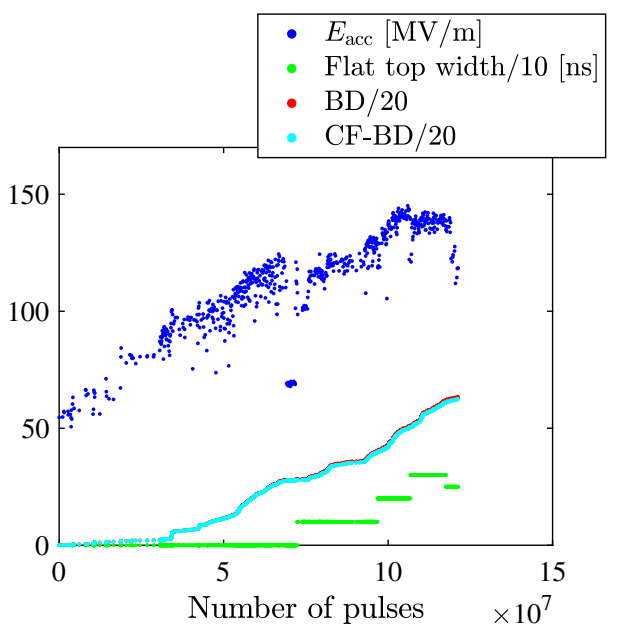

FIG. 20. Summary of the conditioning history of THU-REF. The blue dots denote $E_{\mathrm{acc}}[\mathrm{MV} / \mathrm{m}]$, the green dots denote flat top pulse width [ns] divided by 10 , the red dots denote total breakdown number divided by 20 , and the cyan dots denote number of CF-BDs divided by 20 .

\section{POST-MORTEM OF CHOKE-MODE ACCELERATING STRUCTURES}

Inner surface observations were conducted for THUCHK-\#1 and THU-CHK-\#3 as different conditioning histories were observed in the high-gradient tests.

\section{A. Observing results of THU-CHK-\#1}

THU-CHK-\#1 was cut twice along the B1 and B2 line, as shown in Fig. 21(a). The two parts of the structure were observed after the first cut along the B1 line. The results are shown in Fig. 22. The choke slot area in view a and the outer side of the structure in view $b$ were rough. The iris area and cylinder cavity area were smooth.

The two parts after cutting along the B2 line were shown in Fig. 23. The end portion is extremely smooth, maintains a mirrored state, while the inner diameter area is rough. KEYENCE VE-8800 electron microscope was applied to observed the inner surface. The results are shown in Fig. 23.

Severe breakdowns occurred in the choke but not in the iris or cylinder cavity area. The damages in the choke were evenly distributed along the circumference. It indicated that
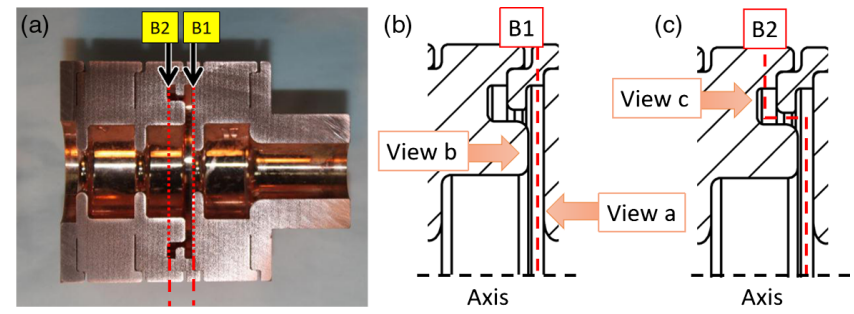

FIG. 21. Cut and observation view of THU-CHK-\#1. (a) Cutting scheme. (b) Observation view after the first cut. (c) Observation view after the second cut.

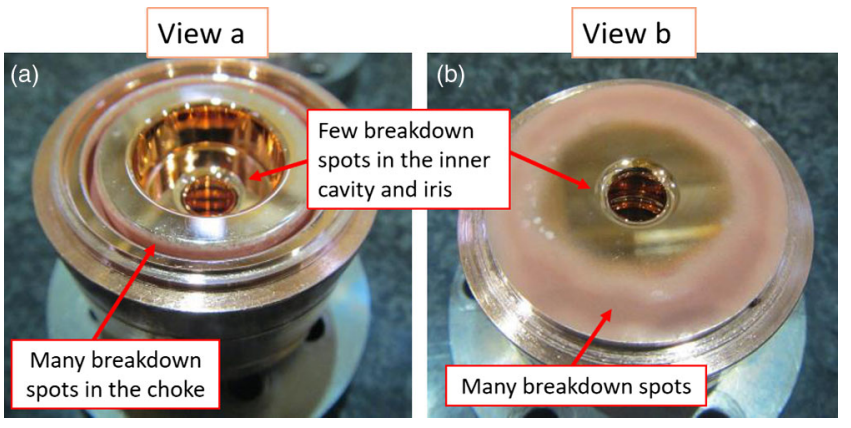

FIG. 22. THU-CHK-\#1 after the cut along B1 line. (a) Observation results of the view a of Fig. 21(b) Observation results of the view b of Fig. 21.

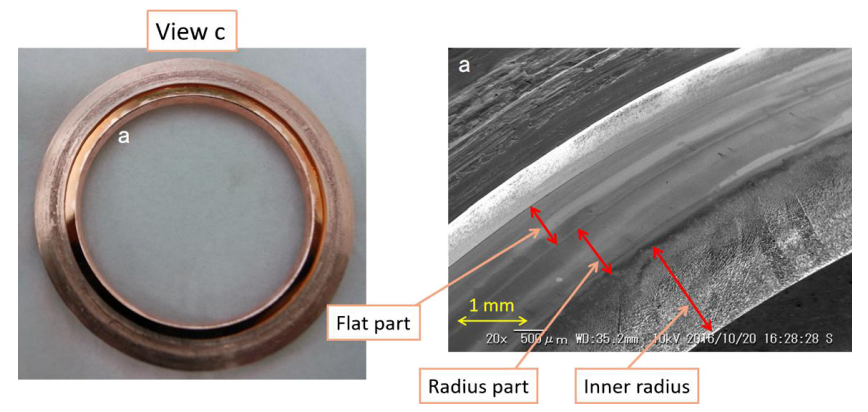

FIG. 23. THU-CHK-\#1 after the cut along B2 line. Left is the ring part after cutting along the B1 and B2 line. Observing from view c shown in Fig. 21. Right is the SEM observing results of point a of the ring. Viewing point a head-on when tilted at an angle of $50^{\circ}$.

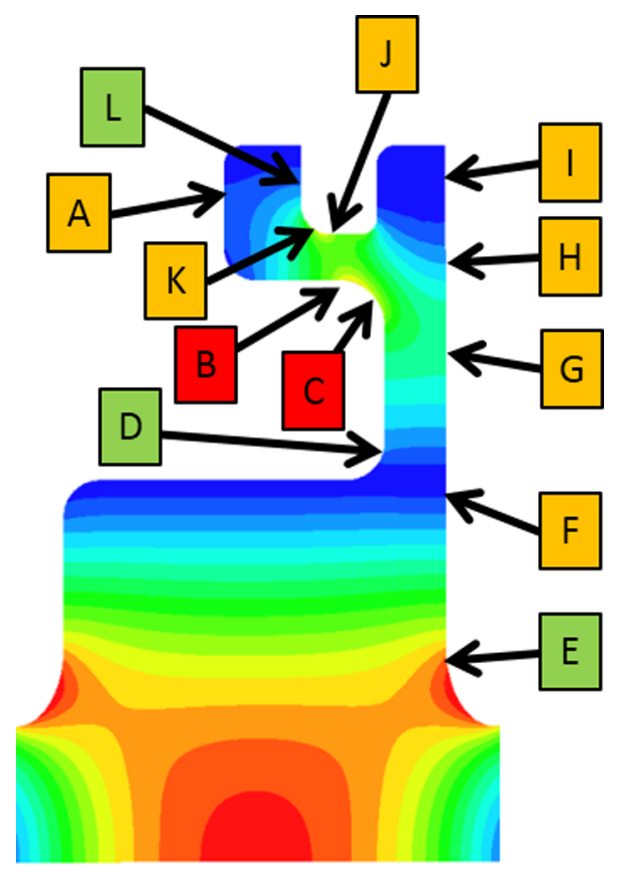

FIG. 24. Surface observation spots of THU-CHK-\#1. Twelve spots were selected counterclockwise. The background of the structure was the electrical field distribution. 

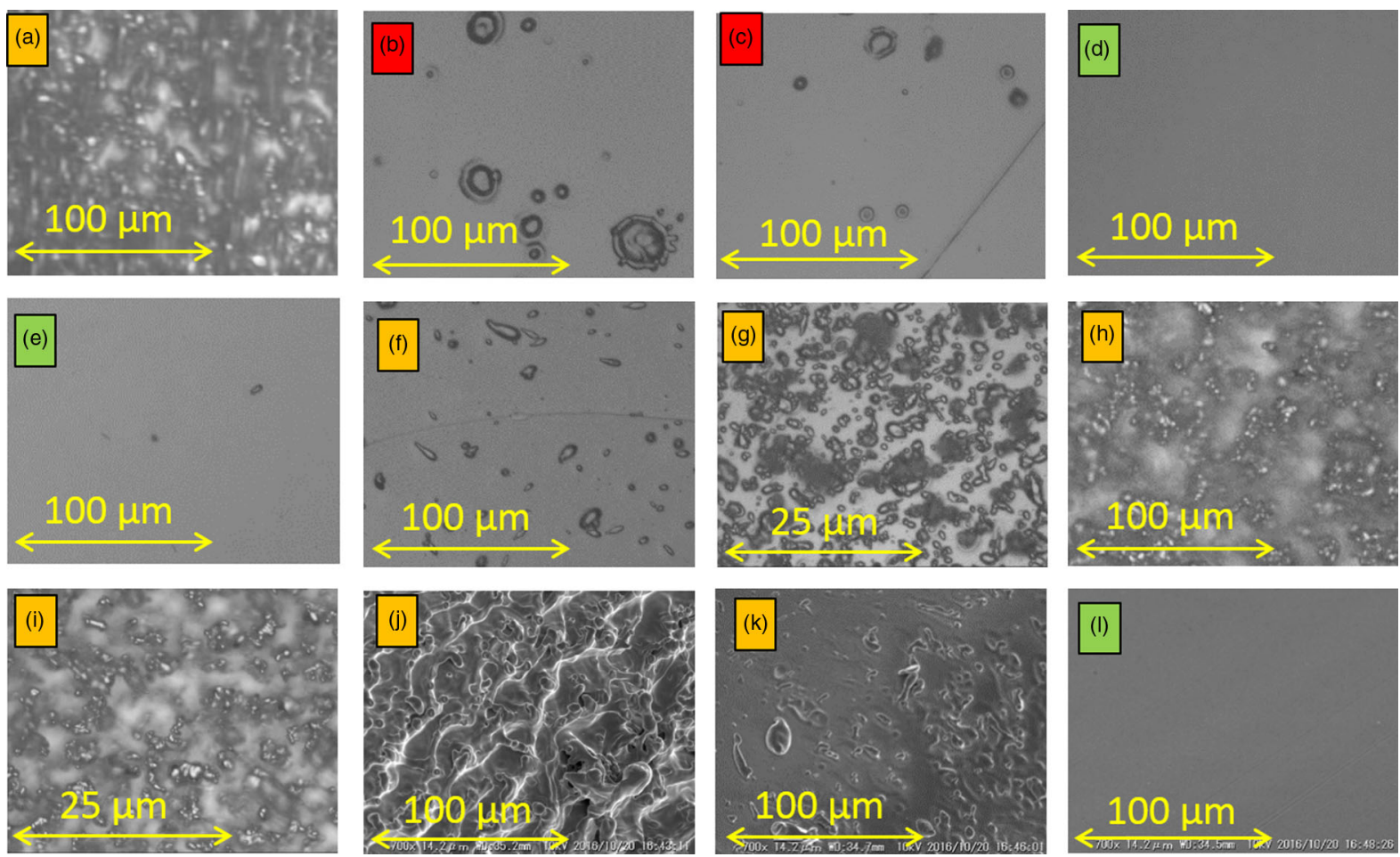

FIG. 25. SEM observation results of the inner surface of THU-CHK-\#1 after the high-gradient test. (A-L) are the selected spots shown in Fig. 24.

breakdowns in the choke are the main limitation to increase the accelerating gradient of the structure.

Twelve spots were selected for SEM observation and study the breakdown in the choke-mode accelerating structure, as shown in Fig. 24. Observation results were shown in Fig. 25.

Severe breakdowns occurred at B, C, and J points from the observation results. Similar sputtering characteristic were observed at $\mathrm{A}, \mathrm{F}, \mathrm{G}, \mathrm{H}, \mathrm{I}$, and $\mathrm{K}$ points while no breakdown was seen at $\mathrm{E}$ point which was located at the iris. It indicated that breakdown events were mainly occurred in the $\mathrm{B}$ and $\mathrm{J}$ point of the choke. This area was far from the cavity axis. Field emission current emitted from the choke could not be collected by the Faraday cups at the power feed end and power cut end. Therefore, rf breakdown events without field emission current flash were observed in the high-gradient test.
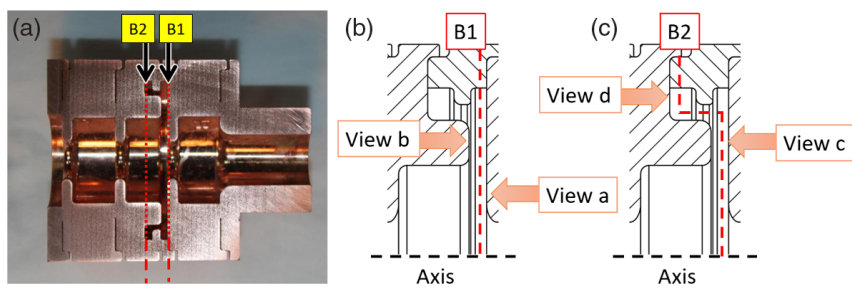

FIG. 26. Cut and observation view of THU-CHK-\#3. (a) Cutting scheme. (b) Observation view after the first cut. (c) Observation view after the second cut.
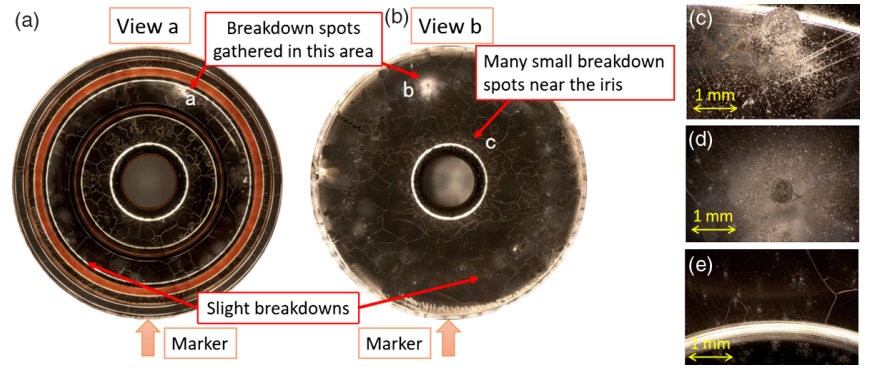

FIG. 27. THU-CHK-\#3 after the cut along the B1 line. (a) Observation results of the view a of Fig. 21. (b) Observation results of the view b of Fig. 21. (c) Zoom of the breakdowns at point a. (d) Zoom of the breakdowns at point b. (e) Zoom of the iris region at point $\mathrm{c}$.
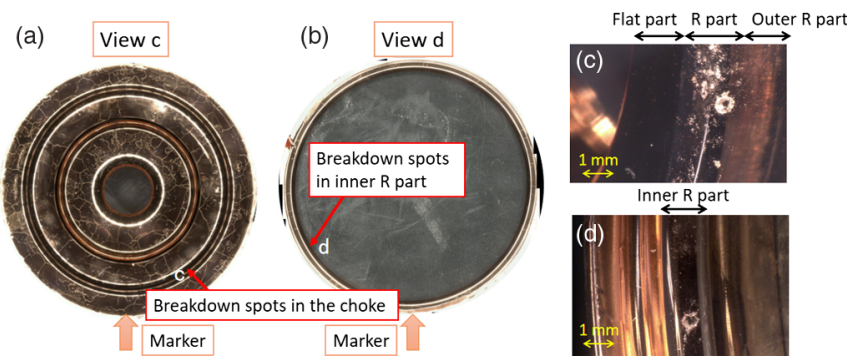

FIG. 28. THU-CHK-\#3 after the cut along the B2 line. (a) Observation results of the view c in Fig. 21. (b) Observation results of the view d in Fig. 21. (c) Zoom of the choke slot and inner area in point c. (d) Zoom of the inner part of the ring in point d. 


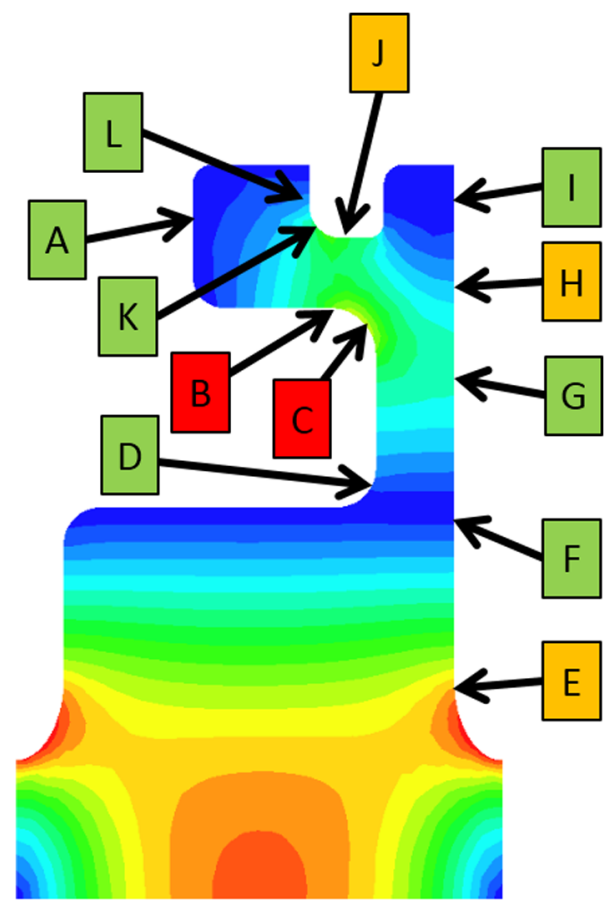

FIG. 29. Surface observation spots of THU-CHK-\#3. Twelve spots were selected counterclockwise. The background of the structure was the electrical field distribution.

High electrical field may have caused severe breakdowns in the choke. High field emission current melted the copper on the choke surface and formed a plasma when breakdown occurred. The melted copper was sputtered to the area adjacent to choke and caused the sputtering characteristics shown in Fig. 25. The severe rf breakdowns in the choke limited the further increase of the accelerating gradient and kept the cylinder cavity to be operate at a low power level. Thus no concentrated breakdown spots were observed in the iris area.

\section{B. Observing results of THU-CHK-\#3}

THU-CHK-\#3 was cut twice for the inner surface observation by following the same procedures of THU-CHK-\#1, as shown in Fig. 26. The two parts after cutting along the B1 line were observed from the view shown in Fig. 26(b). The results of the observation are shown in Fig. 27. The inner surface of THU-CHK-\#3 appeared more smooth than THUCHK-\#1. Slight breakdown spots were seen in the choke, indicating that choke was still the main area for breakdowns. Another region was observed to have concentrated breakdown spots, as shown by point $a$ and point $b$ in the figure (the two points $\mathrm{a}$ and $\mathrm{b}$ are corresponding points in the original structure). Scratches were observed at point a which were speculated to be created in the machining process. The uneven surface led to a high field enhancement factor in the region, which became a hot spot in high-gradient test. It might be the reason for more rf breakdowns in this region. The numerous breakdown spots in the iris area indicated that breakdown occurred in the cylindrical cavity and choke. The post-mortem result is consistent with the high-gradient test
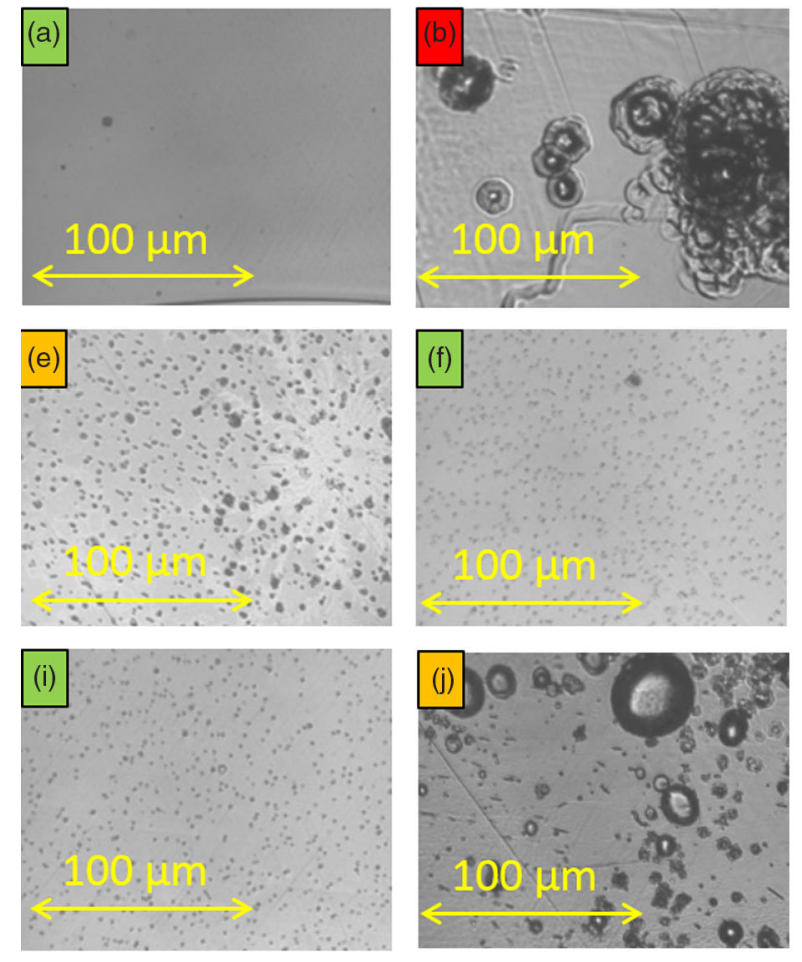
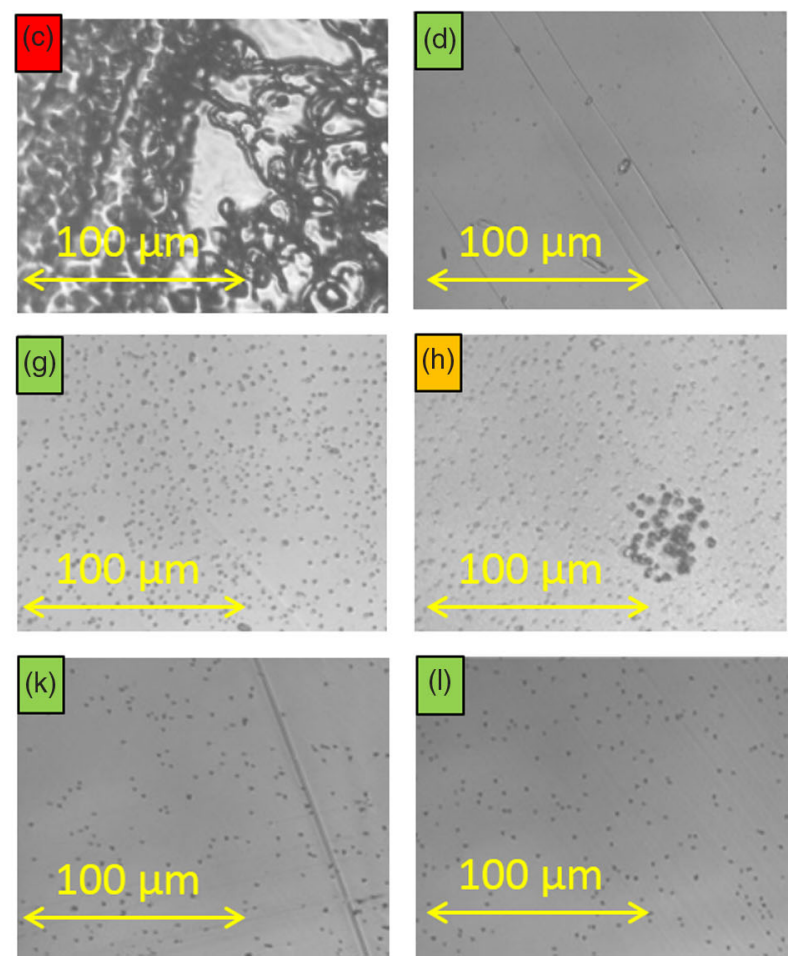

FIG. 30. SEM observation results of the inner surface of THU-CHK-\#3 after the high-gradient test. (A-L) are the selected spots shown in Fig. 29. 
result that the breakdown with and without current flash were accompanied with each other.

The two parts after cutting along the B2 line are shown in Fig. 28. Breakdowns were occurred at the inner part of choke from the view c. The zoom was shown in Fig. 28(c).

The side part of the ring in view $\mathrm{d}$ was smooth, but the inner radius was rough. Severe breakdowns were seen in the zoomed image of the inner radius part, as shown in Fig. 28(d).

Twelve spots were selected for SEM observation and for exploring the breakdown characteristics, as shown in Fig. 29. The observation results were shown in Fig. 30.

Breakdown spots were observed at B, C, and J points and sputtering characters at $\mathrm{F}, \mathrm{G}, \mathrm{H}$, and I points from the observation results of THU-CHK-\#3. Breakdown spots were also observed at $\mathrm{E}$ point which was the iris area. It indicated that the iris and choke breakdowns limited the gradient together. It kept consistent with the high-gradient experimental results.

\section{HIGH-GRADIENT PERFORMANCE}

The summary of the conditioning history of the singlecell structures is shown in Fig. 31. The green, red, blue, cyan, magenta, and black points represent the accelerating gradient of THU-REF, THU-CHK-\#1, THU-K-\#2, THUCHK-\#3, THU-CHK-\#4, and THU-CHK-\#5. THU-REF reached the highest accelerating gradient of $145 \mathrm{MV} / \mathrm{m}$, which validated the Tsinghua $X$-band single-cell structure manufacturing technology. The last three choke-mode accelerating structures reached over $100 \mathrm{MV} / \mathrm{m}$, which was higher than the structures with the choke gap of $1.26 \mathrm{~mm}$ (THU-CHK-\#1 and THU-CHK-\#2). This revealed that BDR can be reduced by increasing the choke gap size and decreasing the electrical field in the choke.

BDR measurements were conducted in the final stages of high-gradient testing for each structure. Input power was

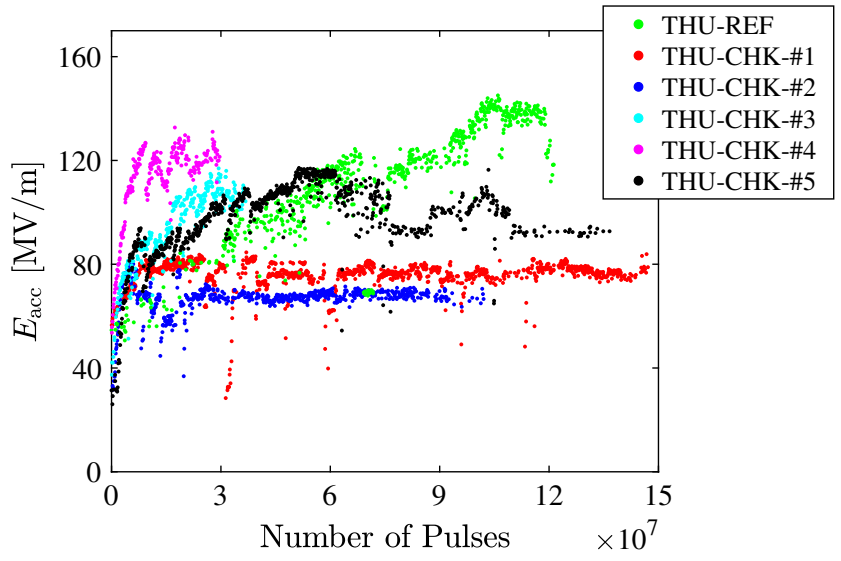

FIG. 31. High-gradient testing history of single-cell structures. The green, red, blue, cyan, magenta, and balck points represent the $E_{\text {acc }}$ of THU-REF, THU-CHK-\#1, THU-CHK-\#2, THUCHK-\#3, THU-CHK-\#4, and THU-CHK-\#5 with respect to the numbe of pulses.
TABLE II. BDR measurements of the single-cell structures.

\begin{tabular}{lcccc}
\hline \hline $\begin{array}{l}\text { THU- } \\
\text { CHK }\end{array}$ & $\begin{array}{c}E_{\text {acc }} \\
{[\mathrm{MV} / \mathrm{m}]}\end{array}$ & $\begin{array}{c}\text { Number of } \\
\text { pulses }\end{array}$ & $\begin{array}{c}\text { Number of } \\
\text { breakdowns }\end{array}$ & $\begin{array}{c}\text { Flat top pulse } \\
\text { width [ns] }\end{array}$ \\
\hline$\# 1$ & 77.3 & $8.93 \times 10^{5}$ & 2 & 200 \\
$\# 2$ & 67.1 & $4.19 \times 10^{6}$ & 16 & 200 \\
$\# 3$ & 105 & $6.14 \times 10^{5}$ & 3 & 250 \\
$\# 4$ & 121 & $2.17 \times 10^{6}$ & 15 & 250 \\
$\# 5$ & 92.2 & $2.01 \times 10^{7}$ & 11 & 200 \\
\hline \hline
\end{tabular}

kept constant in the BDR runs, during the period of operation time when BDR was being evaluated. By counting the breakdown events that occurred in the given period of rf-on time, the BDR was calculated as the number of breakdowns per pulse per metre in the structure [62]. The results are shown in Table II.

BDR is strongly dependent on $E_{\text {acc }}$ and rf pulse width. The dependencies that have been observed in many CLIC prototype structures are reported in Refs. [59,62] and can be approximated with the following relation:

$$
\frac{\mathrm{BDR}}{E_{\mathrm{acc}}^{30} \cdot \tau^{5}}=\mathrm{constant}
$$

where $\tau$ is the pulse width. We can normalize the $E_{\text {acc }}$ to a flat top pulse width of $250 \mathrm{~ns}$ and a breakdown rate of $2 \times 10^{-5}$ per pulse, which is a typical status during the highgradient test, to make comparison among the structures. The maximum electrical field in the choke $\left(E_{\text {choke }}{ }^{\max }\right)$ can be calculated based on this quantity. The normalized accelerating gradient $\left(E_{\text {acc }}{ }^{*}\right)$ and $E_{\text {choke }}{ }^{\max }$ are shown in Table III. Many rf breakdowns occurred in the chokes of THU-CHK\#1 and THU-CHK-\#2 from the inner surface observations in post-mortem. The first two choke achieved the similar $E_{\text {choke }}{ }^{\max }$, which was about $128 \mathrm{MV} / \mathrm{m}$. The $E_{\text {choke }}{ }^{\max }$ was increased by expanding the choke gap. Then we can define the scaled accelerating gradient $(\mathrm{G})$ as below [37]:

$$
G=\frac{E_{\mathrm{acc}} \cdot \tau^{1 / 6}}{\mathrm{BDR}^{1 / 30}}
$$

where $\mathrm{G}$ represents the high-gradient performance of the accelerating structure during the stable operation stage. $G$ depends on both $R_{\mathrm{c}}$ and choke dimension from previous analysis. The information is shown in Table III.

TABLE III. Choke high-gradient performance comparison.

\begin{tabular}{lccc}
\hline \hline THU-CHK & $E_{\text {acc }}{ }^{*}[\mathrm{MV} / \mathrm{m}]$ & $E_{\text {choke }}{ }^{\max }[\mathrm{MV} / \mathrm{m}]$ & $\mathrm{G}[\mathrm{MV} / \mathrm{m}]$ \\
\hline$\# 1$ & 80.1 & 128 & 250 \\
$\# 2$ & 68.3 & 129 & 213 \\
$\# 3$ & 110 & 163 & 343 \\
$\# 4$ & 125 & 177 & 391 \\
$\# 5$ & 100 & 172 & 312 \\
\hline \hline
\end{tabular}




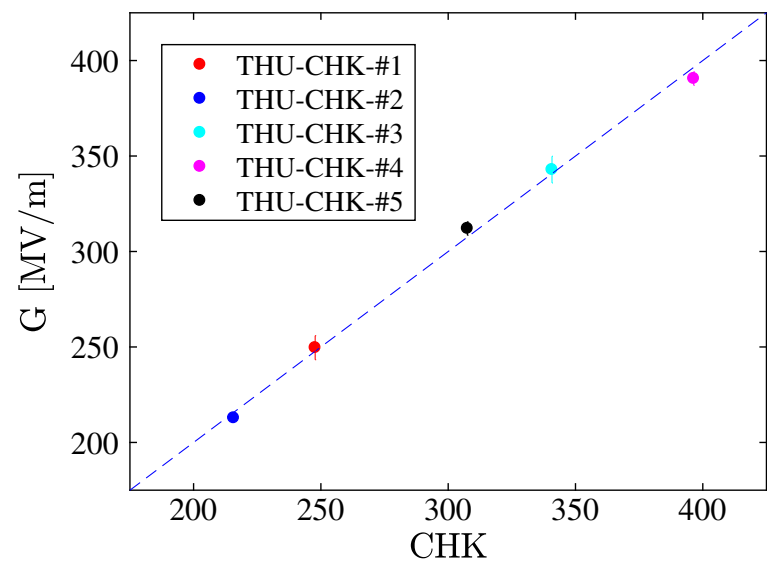

FIG. 32. CHK fitting with the high-gradient experimental data. The red, blue, cyan, magenta, and black points represent the THU-CHK-\#1, THU-CHK-\#2, THU-CHK-\#3, THU-CHK-\#4, and THU-CHK-\#5. The blue dashed line denotes $\mathrm{G}=\mathrm{CHK}$.

A new quantity named $\mathrm{CHK}$ was proposed for the evaluation of the high-gradient performance of choke, as shown below:

$$
\mathrm{CHK}=\left(R_{\mathrm{c}}\right)^{\alpha} \times D^{\beta} \times \gamma .
$$

Meanwhile, $\alpha, \beta$, and $\gamma$ in Eq. (7) can be regulated by applying the high-gradient test results. Fitting results indicated that $\alpha=-0.707, \beta=0.711, \gamma=173$ :

$$
\mathrm{CHK}=\left(R_{\mathrm{c}}\right)^{-0.707} \times D^{0.711} \times 173
$$

Fitting results are shown in Fig. 32. The new quantity CHK can be useful in guiding high-gradient choke-mode accelerating structure design.

\section{SUMMARY}

Five different single-cell choke-mode accelerating structures and one reference structure were designed, fabricated, and subjected to high-gradient tests to study related $\mathrm{rf}$ breakdown characteristics. High electrical field and small choke dimension caused serious breakdowns in the choke. It was the main limitation of the high-gradient performance. THU-CHK-\#4 reached $121 \mathrm{MV} / \mathrm{m}$ at a breakdown rate of $8.30 \times 10^{-4}$ per pulse per meter and a flat top pulse length of $250 \mathrm{~ns}$ by decreasing the electrical field and increasing the choke gap size. A new quantity was proposed to give the high-gradient performance limitation of choke-mode accelerating structures owing to rf breakdown. It could be used to guide high-gradient choke-mode accelerating structure design.

\section{ACKNOWLEDGMENTS}

This work was supported by the National Natural Science Foundation of China (Grant No. 11135004).
The experimental program had also been supported as one of the collaborations of the CLIC under the agreement between Tsinghua University and CLIC and that between KEK and CERN (ICA-JP-0103). The authors thank the KEK electron-positron injector group for supporting the long-term operation.

[1] T. Shintake, The choke mode cavity, Jpn. J. Appl. Phys. 31 (1992).

[2] H. Zha, J. Shi, H. Chen, A. Grudiev, W. Wuensch, C. Tang, and W. Huang, Choke-mode damped structure design for the Compact Linear Collider main linac, Phys. Rev. ST Accel. Beams 15, 122003 (2012).

[3] T. Inagaki, in Proceedings of the 24th International Linear Accelerator Conference, LINAC-2008, Victoria, Canada (JACoW, Victoria, Canada, 2008), pp. 1091-1094.

[4] T. Shintake, H. Tanaka, T. Hara, T. Tanaka, K. Togawa, M. Yabashi, Y. Otake, Y. Asano, T. Bizen, T. Fukui et al., A compact free-electron laser for generating coherent radiation in the extreme ultraviolet region, Nat. Photonics 2, 555 (2008).

[5] T. Shintake, in Proceedings of the 1st International Particle Accelerator Conference, IPAC-2010, Kyoto, Japan (ICR, Kyoto, 2010), pp. 1285-1289.

[6] K. Okihira, F. Inoue, T. Hashirano, and S. Miura, in Proceedings of the 2nd International Particle Accelerator Conference, IPAC-2011, San Sebastián, Spain (EPS-AG, Spain, 2011), pp. 1737-1739.

[7] T. Ishikawa, H. Aoyagi, T. Asaka, Y. Asano, N. Azumi, T. Bizen, H. Ego, K. Fukami, T. Fukui, Y. Furukawa et al., A compact X-ray free-electron laser emitting in the subångström region, Nat. Photonics 6, 540 (2012).

[8] J. Shi, H. Zha, A. Grudiev, and W. Wuensch, in Proceedings of the 2nd International Particle Accelerator Conference, IPAC-2011, San Sebastián, Spain (EPS-AG, Spain, 2011), pp. 113-115.

[9] H. Zha, H. Chen, C. Tang, and W. Huang, in Proceedings of the 3rd International Particle Accelerator Conference, IPAC-2012, New Orleans, LA (IEEE, Piscataway, NJ, 2012), pp. 1840-1842.

[10] H. Zha, J. Shi, and H. Chen, in Proceedings of the 4th International Particle Accelerator Conference, IPAC2013, Shanghai, China (JACoW, Shanghai, China, 2013), pp. 1628-1630.

[11] X. Wu, H. Zha, J. Shi, and H. Chen, in Proceedings of the 4th International Particle Accelerator Conference, IPAC2013, Shanghai, China (JACoW, Shanghai, China, 2013), pp. 2774-2776.

[12] H. Zha, J. Shi, X. Wu, and H. Chen, Higher-order mode absorption measurement of $X$-band choke-mode cavities in a radial line structure, Nucl. Instrum. Methods Phys. Res., Sect. A 814, 90 (2016).

[13] H. Zha, C. Jing, J. Qiu, E. E. Wisniewski, M. Conde, J. G. Power, D. S. Doran, W. Liu, J. Shi, C. Li, W. Gai, and H. Chen, Beam-induced wakefield observation in $X$-band choke-mode cavities, Phys. Rev. Accel. Beams 19, 081001 (2016). 
[14] R. Tomás, Overview of the compact linear collider, Phys. Rev. ST Accel. Beams 13, 014801 (2010).

[15] M. Aicheler et al., A multi-TeV linear collider based on CLIC technology: CLIC conceptual design report, CERN Technical Report No. CERN-2012-007, 2012.

[16] M. Boland et al., Updated baseline for a staged Compact Linear Collider, CERN Technical Report No. CERN-2016004, 2016.

[17] S. Döbert, A. Grudiev, G. Riddone, and W. Wuensch, in Proceedings of the 25th International Linear Accelerator Conference, LINAC-2010 (JACoW, Tsukuba, Japan, 2010), pp. 208-210.

[18] A. Grudiev and W. Wuensch, in Proceedings of the 22nd International Linear Accelerator Conference, LINAC2004 (JACoW, Lübeck, Germany, 2004), pp. 779-781.

[19] A. Grudiev and W. Wuensch, in Proceedings of the 24th International Linear Accelerator Conference, LINAC2008 (JACoW, Victoria, BC, Canada, 2008), pp. 933-935.

[20] A. Grudiev and W. Wuensch, in Proceedings of the 25th International Linear Accelerator Conference, LINAC2010 (JACoW, Tsukuba, Japan, 2010), pp. 211-213.

[21] H. Zha and A. Grudiev, Design and optimization of Compact Linear Collider main linac accelerating structure, Phys. Rev. Accel. Beams 19, 111003 (2016).

[22] A. Degiovanni, S. Döebert, W. Farabolini, and W. Wuensch, in Proceedings of the 5th International Particle Accelerator Conference, IPAC-2014, Dresden, Germany (JACoW, Dresden, Germany, 2014), pp. 2285-2287.

[23] P. Wang, H. Zha, I. Syratchev, J. Shi, and H. Chen, rf design of a pulse compressor with correction cavity chain for klystron-based compact linear collider, Phys. Rev. Accel. Beams 20, 112001 (2017).

[24] H. Zha and A. Grudiev, Design of the Compact Linear Collider main linac accelerating structure made from two halves, Phys. Rev. Accel. Beams 20, 042001 (2017).

[25] H. Zha, A. Grudiev, and V. A. Dolgashev, in Proceedings of the 6th International Particle Accelerator Conference, IPAC-2015, Richmond, VA, USA (JACoW, Richmond, VA, USA, 2015), pp. 2147-2149.

[26] W. Wuensch, N. Catanlan-Lasheras, A. Grudiev, and G. Mcmonagle, in Proceedings of the 28th International Linear Accelerator Conference, LINAC-2016 (JACoW, East Lansing, MI, USA, 2016), pp. 533-535.

[27] B. Woolley, I. Syratchev, and A. Dexter, Control and performance improvements of a pulse compressor in use for testing accelerating structures at high power, Phys. Rev. Accel. Beams 20, 101001 (2017).

[28] R. M. Jones, Wakefield suppression in high gradient linacs for lepton linear colliders, Phys. Rev. ST Accel. Beams 12, 104801 (2009).

[29] R. M. Jones, C. E. Adolphsen, J. W. Wang, and Z. Li, Wakefield damping in a pair of $X$-band accelerators for linear colliders, Phys. Rev. ST Accel. Beams 9, 102001 (2006).

[30] V. Khan, A. D’Elia, R. M. Jones, A. Grudiev, W. Wuensch, G. Riddone, and V. Soldatov, Wakefield and surface electromagnetic field optimisation of manifold damped accelerating structures for CLIC, Nucl. Instrum. Methods Phys. Res., Sect. A 657, 131 (2011).
[31] H. Zha, CLIC Choke-mode structure design and study, Ph.D. thesis, Tsinghua University, Beijing, 2013.

[32] J. Wang and G. Loew, Field emission and rf breakdown in high-gradient room-temperature linac structures, SLAC Report No. 7684, 1997.

[33] C. Adolphsen, W. Baumgartner, K. Jobe, and F. Pimpec, in Proceedings of the 19th Particle Accelerator Conference, Chicago, IL, 2001 (IEEE, Piscataway, NJ, 2001), pp. 478-480.

[34] C. Adolphsen, in Proceedings of the 21st Particle Accelerator Conference, Knoxville, TN, 2005 (IEEE, Piscataway, NJ, 2005), pp. 204-208.

[35] V. A. Dolgashev and T. Raubenheimer, Simulation of rf breakdown effects on NLC beam, SLAC Report No. 10668, 2004.

[36] A. Palaia, M. Jacewicz, R. Ruber, V. Ziemann, and W. Farabolini, Effects of rf breakdown on the beam in the Compact Linear Collider prototype accelerator structure, Phys. Rev. ST Accel. Beams 16, 081004 (2013).

[37] A. Degiovanni, W. Wuensch, and J. Giner Navarro, Comparison of the conditioning of high gradient accelerating structures, Phys. Rev. Accel. Beams 19, 032001 (2016).

[38] W. Wuensch, A. Degiovanni, S. Calatroni, A. Korsbäck, F. Djurabekova, R. Rajamäki, and J. Giner-Navarro, Statistics of vacuum breakdown in the high-gradient and low-rate regime, Phys. Rev. Accel. Beams 20, 011007 (2017).

[39] E. Senes, T. Argyropoulos, F. Tecker, and W. Wuensch, Beam-loading effect on breakdown rate in high-gradient accelerating cavities: An experiment at the Compact Linear Collider Test Facility at CERN, Phys. Rev. Accel. Beams 21, 102001 (2018).

[40] S. A. Barengolts, V. G. Mesyats, V. I. Oreshkin, E. V. Oreshkin, K. V. Khishchenko, I. V. Uimanov, and M. M. Tsventoukh, rf breakdown tests of mm-wave metallic accelerating structures, Phys. Rev. Accel. Beams 21, 061004 (2018).

[41] M. Dal Forno, V. A. Dolgashev, G. Bowden, C. Clarke, M. Hogan, D. McCormick, A. Novokhatski, B. Spataro, S. Weathersby, and S. G. Tantawi, rf breakdown tests of mmwave metallic accelerating structures, Phys. Rev. Accel. Beams 19, 011301 (2016).

[42] M. Dal Forno, V. A. Dolgashev, G. Bowden, C. Clarke, M. Hogan, D. McCormick, A. Novokhatski, B. Spataro, S. Weathersby, and S. G. Tantawi, Experimental measurements of rf breakdowns and deflecting gradients in mmwave metallic accelerating structures, Phys. Rev. Accel. Beams 19, 051302 (2016).

[43] M. Dal Forno, V. A. Dolgashev, G. Bowden, C. Clarke, M. Hogan, D. McCormick, A. Novokhatski, B. O'Shea, B. Spataro, S. Weathersby, and S. G. Tantawi, rf breakdown measurements in electron beam driven $200 \mathrm{GHz}$ copper and copper-silver accelerating structures, Phys. Rev. Accel. Beams 19, 111301 (2016).

[44] M. Dal Forno, V. A. Dolgashev, G. Bowden, C. Clarke, M. Hogan, D. McCormick, A. Novokhatski, B. O'Shea, B. Spataro, S. Weathersby, and S. G. Tantawi, Measurements of electron beam deflection and rf breakdown rate from a surface wave guided in metallic mm-wave accelerating structures, Phys. Rev. Accel. Beams 21, 091301 (2018). 
[45] T. Abe, T. Kageyama, H. Sakai, Y. Takeuchi, and K. Yoshino, Breakdown study based on direct in situ observation of inner surfaces of an rf accelerating cavity during a high-gradient test, Phys. Rev. Accel. Beams 19, 102001 (2016).

[46] T. Abe, T. Kageyama, H. Sakai, Y. Takeuchi, and K. Yoshino, Direct observation of breakdown trigger seeds in a normal-conducting rf accelerating cavity, Phys. Rev. Accel. Beams 21, 122002 (2018).

[47] V. A. Dolgashev, S. G. Tantawi, C. D. Nantista, Y. Higashi, and T. Higo, in Proceedings of the 21st Particle Accelerator Conference, PAC-2005, Knoxville, TN, 2005 (IEEE, Piscataway, NJ, 2005), pp. 595-599.

[48] V. A. Dolgashev, S. G. Tantawi, C. D. Nantista, Y. Higashi, and T. Higo, in Proceedings of the 22nd Particle Accelerator Conference, PAC-2007, Albuquerque, NM (IEEE, New York, 2007), pp. 2430-2432.

[49] V. A. Dolgashev, S. G. Tantawi, C. D. Nantista, and Y. Higashi, Travelling wave and standing wave single cell high gradient tests, SLAC Report No. 10667, 2004.

[50] V. A. Dolgashev, S. G. Tantawi, Y. Higashi, and T. Higo, in Proceedings of the 11th European Particle Accelerator Conference, EPAC-2008, Genoa (EPS-AG, Genoa, Italy, 2008), pp. 742-744.

[51] V. A. Dolgashev, S. G. Tantawi, A. D. Yeremian, and Y. Higashi, in Proceedings of the 1st International Particle Accelerator Conference, IPAC-2010, Kyoto, Japan (ICR, Kyoto, 2010), pp. 3810-3812.

[52] V. A. Dolgashev, S. G. Tantawi, Y. Higashi, and B. Spataro, Geometric dependence of radio-frequency breakdown in normal conducting accelerating structures, Appl. Phys. Lett. 97, 171501 (2010).

[53] T. Abe, Y. Arakida, T. Higo, and S. Matsumoto, in Proceeding of the 12th Annual Meeting of Particle Accelerator Society of Japan, PASJ-2015 (KEK, Tsuruga, Japan, 2015), pp. 607-612.

[54] T. Abe, Y. Arakida, T. Higo, S. Matsumoto, T. Takatomi, X. Wu, J. Shi et al., in Proceedings of the 13th Annual Meeting of Particle Accelerator Society of Japan, PASJ2016 (KEK, Chiba, Japan, 2016), pp. 348-352.

[55] X. Wu, H. Zha, J. Shi, and H. Chen, in Proceedings of the 8th International Particle Accelerator Conference, IPAC-2017, Copenhagen, Denmark (JACoW, Copenhagen, Denmark, 2017), pp. 1322-1325.

[56] S. Matsumoto, M. Akemoto, S. Fukuda, and T. Higo, in Proceedings of the 11th European Particle Accelerator Conference, EPAC-2008, Genoa, Italy (EPS-AG, Genoa, Italy, 2008), pp. 2740-2742.

[57] X. Wu, J. Shi, H. Chen, and T. Higo, in Proceedings of the 7th International Particle Accelerator Conference, IPAC-2016, Busan, Korea (JACoW, Busan, Korea, 2016), pp. 3881-3883.

[58] A. D. Yeremian, V. A. Dolgashev, and S. G. Tantawi, in Proceedings of the 1st International Particle Accelerator
Conference, IPAC-2010, Kyoto, Japan (ICR, Kyoto, 2010), pp. 3822-3824.

[59] A. Grudiev, S. Calatroni, and W. Wuensch, New local field quantity describing the high gradient limit of accelerating structures, Phys. Rev. ST Accel. Beams 12, 102001 (2009).

[60] J. Wang and T. Higo, International Committee for Future Accelerators (ICFA): Beam Dynamics Newsletter No. 32, 27 (2003).

[61] K. Abe et al., GLC project: Linear collider for TeV physics (KEK, Tsukuba, 2003).

[62] X. Wu, J. Shi, H. Chen, J. Shao, T. Abe, T. Higo, S. Matsumoto, and W. Wuensch, High-gradient breakdown studies of an $X$-band Compact Linear Collider prototype structure, Phys. Rev. Accel. Beams 20, 052001 (2017).

[63] V. A. Dolgashev, S. G. Tantawi, Y. Higashi, and B. Spataro, in Proceedings of the 25th International Linear Accelerator Conference, LINAC-2010, Tsukuba, Japan (KEK, Tsukuba, Japan, 2010), pp. 1043-1047.

[64] S. Matsumoto, T. Abe, Y. Higashi, T. Higo, and Y. Du, High gradient test at Nextef and high-power long-term operation of devices, Nucl. Instrum. Methods Phys. Res., Sect. A 657, 160 (2011).

[65] J. Shao, S. P. Antipov, S. V. Baryshev, H. Chen, M. Conde, D. S. Doran, W. Gai, C. Jing, W. Liu, J. Power, J. Qiu, J. Shi, D. Wang, F. Wang, C. E. Whiteford, E. Wisniewski, and L. Xiao, Observation of Field-Emission Dependence on Stored Energy, Phys. Rev. Lett. 115, 264802 (2015).

[66] J. Shao, J. Shi, S. P. Antipov, S. V. Baryshev, H. Chen, M. Conde, W. Gai, G. Ha, C. Jing, F. Wang, and E. Wisniewski, In Situ Observation of Dark Current Emission in a High Gradient rf Photocathode Gun, Phys. Rev. Lett. 117, 084801 (2016).

[67] T. Argyropoulos, N. Catalan-Lasheras, A. Grudiev, G. Mcmonagle, E. Rodriguez-Castro, I. Syrachev, R. Wegner, B. Woolley, W. Wuensch, H. Zha, V. Dolgashev, G. Bowden, A. Haase, T. G. Lucas, M. Volpi, D. EsperantePereira, and R. Rajamäki, Design, fabrication, and highgradient testing of an $X$-band, traveling-wave accelerating structure milled from copper halves, Phys. Rev. Accel. Beams 21, 061001 (2018).

[68] Q. Chen, T. Hu, B. Qin, Y. Xiong, K. Fan, and Y. Pei, rf conditioning and breakdown analysis of a traveling wave linac with collinear load cells, Phys. Rev. Accel. Beams 21, 042003 (2018).

[69] R. Zennaro, H. Blumer, M. Bopp, and T. Garvey, in Proceedings of the 8th International Particle Accelerator Conference, IPAC-2017, Copenhagen, Denmark (JACoW, Copenhagen, Denmark, 2017), pp. 4318-4320.

[70] X. Wu, J. Shi, H. Chen, and T. Higo, in Proceedings the 7th International Particle Accelerator Conference, IPAC-2016, Busan, Korea (JACoW, Busan, Korea, 2016), pp. 3874 3877. 